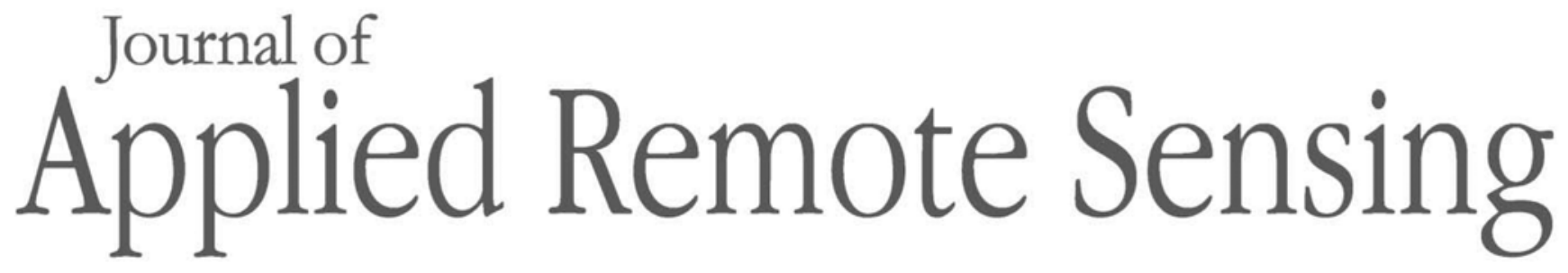

RemoteSensing.SPIEDigitalLibrary.org

\title{
Diurnal changes in ocean color sensed in satellite imagery
}

Robert Arnone

Ryan Vandermuelen

Inia Soto

Sherwin Ladner

Michael Ondrusek

Haoping Yang 


\title{
Diurnal changes in ocean color sensed in satellite imagery
}

\author{
Robert Arnone, ${ }^{\mathrm{a}, *}$ Ryan Vandermuelen, ${ }^{\mathrm{b}}$ Inia Soto, ${ }^{\mathrm{a}}$ Sherwin Ladner, \\ Michael Ondrusek, ${ }^{\mathrm{d}}$ and Haoping Yang ${ }^{\mathrm{a}, \mathrm{e}}$ \\ ${ }^{a}$ University of Southern Mississippi, School of Ocean Science and Technology, \\ Division of Marine Science, Stennis Space Center Mississippi, United States

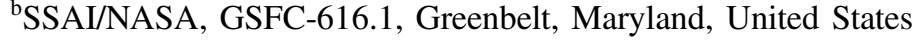 \\ ${ }^{c}$ Naval Research Laboratory, Stennis Space Center, Mississippi, United States \\ ${ }^{\mathrm{d} N O A A / N E S D I S / S T A R, ~ C e n t e r ~ f o r ~ W e a t h e r ~ a n d ~ C l i m a t e ~ P r e d i c t i o n, ~}$ \\ College Park, Maryland, United States \\ ${ }^{\mathrm{e} B a n z a n}$ International Group Corporation, Acton, Massachusetts, United States
}

\begin{abstract}
Measurements of diurnal changes in ocean color in turbid coastal regions in the Gulf of Mexico were characterized using above water spectral radiometry from a National Aeronautics and Space Administration (aerosol robotic network-WaveCIS CSI-06) site that can provide 8 to 10 observations per day. Satellite capability to detect diurnal changes in ocean color was characterized using hourly overlapping afternoon orbits of the visual infrared imaging radiometer suite (VIIRS) Suomi National Polar-orbiting Partnership ocean color sensor and validated with in situ observations. The monthly cycle of diurnal changes was investigated for different water masses using VIIRS overlaps. Results showed the capability of satellite observations to monitor hourly color changes in coastal regions that can be impacted by vertical movement of optical layers, in response to tides, resuspension, and river plume dispersion. The spatial variability of VIIRS diurnal changes showed the occurrence and displacement of phytoplankton blooming and decaying processes. The diurnal change in ocean color was above $20 \%$, which represents a $30 \%$ change in chlorophyll-a. Seasonal changes in diurnal ocean color for different water masses suggest differences in summer and winter responses to surface processes. The diurnal changes observed using satellite ocean color can be used to define the following: surface processes associated with biological activity, vertical changes in optical depth, and advection of water masses. (C) The Authors. Published by SPIE under a Creative Commons Attribution 3.0 Unported License. Distribution or reproduction of this work in whole or in part requires full attribution of the original publication, including its DOI. [DOI: 10.1117/1.JRS.11.032406]
\end{abstract}

Keywords: ocean color; remote sensing; optics; satellites, validation; diurnal; uncertainty; Suomi National Polar-orbiting Partnership visual infrared imaging radiometer suite; aerosol robotic network; orbit overlap; geostationary coastal and air pollution events.

Paper 16925SSP received Dec. 2, 2016; accepted for publication Apr. 11, 2017; published online May 9, 2017.

\section{Introduction}

The color of ocean water can change rapidly throughout the day, especially in coastal areas where dynamic ocean processes occur. ${ }^{1}$ Ocean color is defined as the spectral water-leaving radiance $\left(n L_{\mathrm{w}}\right)$ or remote sensing reflectance $\left(R_{\mathrm{rs}}\right)$ and is used to define water properties including chlorophyll-a and inherent optical properties, such as absorption and scattering. ${ }^{2-4}$ Changes in the color of the ocean water can occur on daily, hourly, and subhourly scales as a result of (1) advection of water masses, such as fronts and river plumes that respond to wind events, tidal forcing, and dynamic circulation events, ${ }^{5}$ (2) water mass bio-geo-optical changes that include the growth and decay of phytoplankton blooms; ${ }^{6}$ (3) upwelling and downwelling of vertical optical layers; ${ }^{7-10}$ and (4) particle settling and resuspension events. ${ }^{11-13}$ The changes in vertical

*Address all correspondence to: Robert Arnone, E-mail: Robert.Arnone@usm.edu 
optical thin layers occurring throughout the day respond to both physical processes (mixed layer depth, mixing, etc.) and migration of swimming organisms, ${ }^{14}$ and these vertical layers within the first optical depth can influence the water color as sensed from spaceborne radiometry. ${ }^{15}$ Diurnal ocean color changes can also be related to phytoplankton vertical migration. ${ }^{8-10}$ The diurnal nature of these changes in ocean color provides a unique capability to help characterize these shallow vertical processes from radiometric measurements, provided the temporal element of ocean color response is recognized. Diurnal color changes can also support how bio-optics is linked to changes in surface temperature and physical processes from circulation models. ${ }^{3}$

Typically, measurements from sun-synchronous polar-orbiting ocean color sensors are inadequate for resolving dynamic coastal processes due to a lack of temporal coverage (i.e., one visit per day). The calibration and validation of products from ocean color sensors, especially in dynamic coastal areas, do not usually account for the diurnal changes in ocean color and assume a relatively temporally stable daily product $\left( \pm 2 \mathrm{~h}\right.$ ) for calibration procedures. ${ }^{16}$ Previous studies using geostationary satellite measurements have found that large changes in bio-optical parameters, such as water-leaving radiance, ${ }^{17}$ light attenuation, ${ }^{18,19}$ suspended particulate matter, and turbidity, ${ }^{13,20,21}$ can occur on diel timescales and can be very significant; therefore, significant biases may be introduced as a result of having only one sample per day. ${ }^{22}$ Although the temporal coverage of current geostationary orbiting missions, such as the geostationary ocean color imager (GOCI) vastly improves the sampling frequency of these parameters, the limit of geographic coverage constrains the extent of monitoring diurnal processes on global scales. Validation of satellite products requires accounting for the diurnal color variability, especially in coastal areas. In offshore waters, where temporal dynamic processes are reduced, the color signatures are more homogeneous and can be more diurnally stable, therefore, methods for calibration and validation of satellite products are easier and better defined in these spatially and temporally homogenous offshore waters compared with coastal waters with strong diurnal changes ${ }^{23}$ It becomes important to characterize these diurnal changes in coastal waters when taking into account that the timing of satellite overpasses may be influenced by near-surface ocean processes that affect the optical characteristics of the water and are also changing on diurnal timescales, such as surface heating, solar elevation, light penetration, and migration of plankton layers.

Our objective is to examine the diurnal changes in ocean color that can occur in coastal regions and determine the capability of the present polar-orbiting satellites to identify and validate these changes. We will examine present National Aeronautics and Space Administration (NASA) aerosol robotic network (AERONET) SeaWiFS photometer revision for incident surface measurements (SeaPRISM) data at WaveCIS (CSI-06) in the northern Gulf of Mexico, which are used for satellite ocean color calibration and validation in coastal areas, to determine the diurnal changes in ocean color. We compare these observations with measurements from the consecutive overlapping orbits of the visual infrared imaging radiometer suite (VIIRS) Suomi National Polar-orbiting Partnership (SNPP) to determine the capability to examine diurnal changes in ocean color imagery at the same geographic location using the same sensor and characterize the uncertainty of the VIIRS diurnal overlap products. Our efforts will validate the use of ocean color diurnal products in coastal regions to demonstrate the changes in ocean color that can occur in dynamic coastal regions such as the northern Gulf of Mexico and highlight the need for additional temporal coverage across the diurnal timescale. New ocean products will be demonstrated using the satellite diurnal changes in ocean color that identify regions of biological blooming and decaying, movement in optical depth, and physical water mass advection.

\section{Methods}

\subsection{Study Area}

The study area is focused on the central northern Gulf of Mexico $\left(87\right.$ to $92^{\circ} \mathrm{W}, 28$ to $30.5^{\circ} \mathrm{N}$; Fig. 1). Monthly analysis of the diurnal changes in the ocean color included three regions located outside the main region: open ocean (box A, Fig. 1), West Florida shelf (box B, Fig. 1), and coastal waters (box C, Fig. 1). Figure 1 shows the Gulf of Mexico, boxes for monthly analysis, 


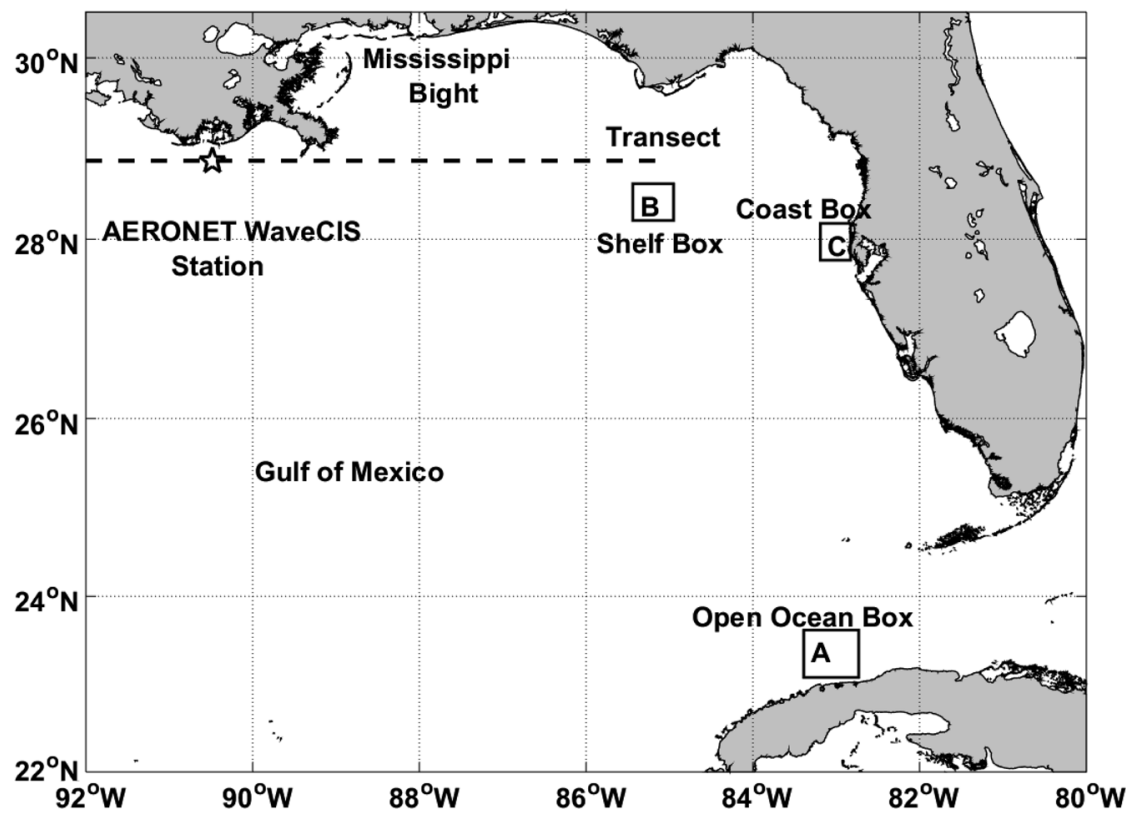

Fig. 1 Study area map showing the AERONET WaveCIS station, transect, and box locations where data were extracted.

and WaveCIS station. The northern Gulf of Mexico is located in a river-dominated region of the coastal Mississippi River turbid waters. Several validation stations used in this study are located in the Mississippi bight, which receives freshwater discharge from the Mississippi River, Mobile Bay, Lake Pontchartrain, and the Pearl, Jourdan, Pascagoula, and Biloxi Rivers.

\subsection{Aerosol Robotic Network Data}

The AERONET SeaPRISM at WaveCIS site (WaveCIS_Site_CSI_6: $90.483^{\circ} \mathrm{W}, 28.867^{\circ} \mathrm{N}$ ) has been reporting the daily normalized water-leaving radiance $\left(n L_{\mathrm{w}}\right)$ at $411,442,491,530,555$ 668,869 , and $1020 \mathrm{~nm}$ from 2010 to 2016 . The SeaPRISM sensor is annually calibrated by NASA to provide consistency between all ocean color AERONET stations around the globe. The WaveCIS site shows good and consistent matchups with ocean color sensors ${ }^{24-27}$ and it is used for continued validation of the VIIRS sensor. WaveCIS collects measurements daily at 15- to 30-min increments on a continual basis throughout the day. SeaPrism data are sent to NASA-AERONET, where the data are processed and screened from level 1 to remove corrupt data, such as surface glint, cloud shadows, and others. ${ }^{28-31}$ AERONET data processing has been standardized for all SeaPrism sites, which have specific protocols for their installation and data processing. ${ }^{29,32}$

\subsection{Satellite Ocean Color}

Satellite ocean color imagery from the VIIRS SNPP was downloaded from the National Oceanographic and Atmospheric Administration (NOAA) comprehensive large array-data stewardship system website and processed to level 3 at 750-m resolution using the Naval Research Laboratories' N2gen code based on NASA's L2gen software ${ }^{33}$ to derive the bio-optical properties for each orbit so that the changes in the satellite water-leaving radiance $\left(n L_{\mathrm{w}}\right)$ and changes in the bio-optical properties could be evaluated..$^{25,26,34}$ The scenes were processed using standard ${ }^{35}$ atmospheric correction at a resolution of $750 \mathrm{~m}$, utilizing multiscattering and iterative nearinfrared atmospheric correction. ${ }^{36-38}$ Standard flags were used to mask contamination from land, clouds, sun glint, and other potential disturbances to the radiance signal.

The overlapping images from sequential VIIRS orbits allow two images to be obtained from the same geographic location on the same day. The unique wider swath of VIIRS has consecutive orbital overlap, where ocean color coverage is collected at the same location from orbit 1 and 

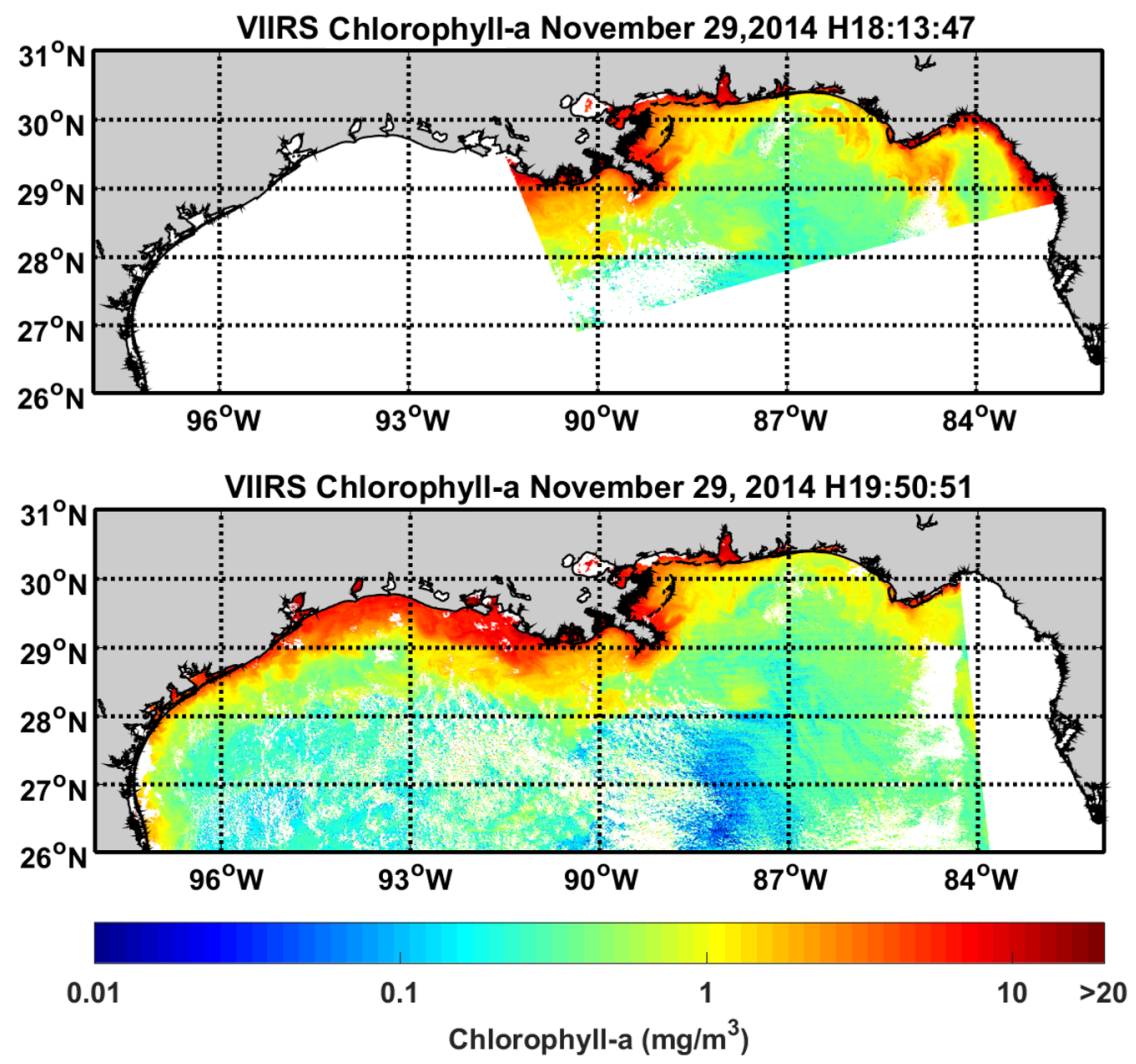

Fig. 2 VIIRS overlapping orbits for November 29, 2014 at hour 18:13:47 (GMT) and 19:50:51 (GMT). The colors represent the chl-a concentration. White color represents cloud, invalid, or no data pixels.

orbit 2 within $\sim 100$ min of each other. The dual VIIRS orbits coverage area within the Gulf of Mexico represents $\sim 55$ to $70 \mathrm{deg}$ sensor zenith angle on the left and right side of the swath and has a coverage area of $\sim 500$ nautical miles as shown in Fig. 2 for November 29, 2014. Near $30^{\circ}$ $\mathrm{N}$, VIIRS orbital overlap repeats for the same geographic area approximately every 4 to 5 days. The moderate-resolution imaging spectroradiometer onboard the aqua satellite (MODIS-aqua) orbit is near the same time period in the afternoon. However, evaluating two sensors, such as MODIS and VIIRS for diurnal ocean color changes can be challenging because they have different sensors' characteristics with slightly different spectral channels and calibration. The diurnal changes sensed using the same VIIRS sensor with a similar consistent calibration and sensor characteristics reduce intersensor uncertainty.

\subsection{Aerosol Robotic Network and Visual Infrared Imaging Radiometer Suite Matchups}

VIIRS chlorophyll-a, $n L_{\mathrm{w}}$ at 443 and $551 \mathrm{~nm}$ were compared with the WaveCIS station $n L_{\mathrm{w}}{ }^{28}$ at the nearest wavelengths (442 and $551 \mathrm{~nm}$ ) and chlorophyll-a from ocean color for three dates: October 11, 2014; December 9, 2014; and December 25, 2014. For each matchup using the center pixel, the chlorophyll-a difference between orbit 1 and orbit 2 was calculated.

To evaluate the accuracy of VIIRS ocean color products between the orbital overlap imagery, we evaluated the influence of the changes across the sensor zenith angles by examining extracted satellite data along a latitudinal transect line from east $\left(85^{\circ} \mathrm{W}\right)$ to west $\left(92^{\circ} \mathrm{W}\right)$ that crosses the WaveCIS station at $28.867^{\circ} \mathrm{N}$ and covers $\sim 55 \mathrm{deg}$ to $70 \mathrm{deg}$ satellite zenith angle for each orbit. For this exercise, we selected the VIIRS data for November 29, 2014. At the overlap regions, the sensor zenith angle from Nadir for orbit 1 (18:13:47 GMT) was westward and for orbit 2 (19:50:31 GMT) was eastward. Along each transect, zenith angle, chlorophyll-a, $n L_{\mathrm{w}}$ at 443 and $n L_{\mathrm{w}}$ at $551 \mathrm{~nm}$, were extracted from the VIIRS overlaps. The differences (orbit 1 and 
orbit 2) between the VIIRS data extracted were calculated. The data at the AERONET WaveCIS site were extracted for $n L_{\mathrm{w}}$ at 442 and $n L_{\mathrm{w}}$ at 551 and derived chlorophyll-a for the same date.

\subsection{Cruise Data and Visual Infrared Imaging Radiometer Suite Matchups}

During the NASA geostationary coastal and air pollution events (GEOCAPE) survey on September 2013 in the northern Gulf of Mexico, stations were collected in coastal waters during VIIRS orbital overlaps using a Satlantic's hyperspectral optical profiler (hyperpro, station B) and floating skylight-blocking approach ${ }^{30,39}$ (station $\mathrm{A}$ ) to determine the $R_{\mathrm{rs}}$ and inherent optical properties (absorption and backscattering). The hyperpro measurements were processed using protocols in Ondrusek et al. ${ }^{40}$ VIIRS center pixel at the stations was used for the matchup.

Additional in situ optical data were collected during the consortium for oil exposure pathways in coastal river-dominated ecosystems (CONCORDE) spring survey on April 3, 2016, near Mobile Bay, Alabama. Radiometric data were collected at four stations using the hyperpro in flotation mode ${ }^{40}$ for near-surface inwater water-leaving radiance.

\subsection{Seasonality in the Ocean Color Diurnal Variability}

To evaluate how the diurnal changes occur in different water masses in the Gulf of Mexico throughout the year, we selected different regions representing: (a) open ocean (b) shelf, and (c) coastal waters (Fig. 1). The open ocean region was located in the Florida Current and covers $\sim 4900 \mathrm{~km}^{2}$. The shelf water region covered $\sim 2500 \mathrm{~km}^{2}$ in the northern Gulf of Mexico ( $300 \mathrm{~km}^{2}$ south of Apalachicola, Florida). The coastal water region was located in the West Florida shelf and covered $\sim 625 \mathrm{~km}^{2}$ offshore Clearwater, Florida. For each region, all the VIIRS data available with two coincidental orbits for each month in 2014 were extracted. The VIIRS data included the $R_{\mathrm{rs}}$ at 410 (M1), 443 (M2), 551 (M4), and 671 (M5) nm, which are labeled, respectively, in the plots. The monthly $R_{\mathrm{rs}}$ mean and monthly $R_{\mathrm{rs}}$ mean difference along with the statistics (standard deviation, maximum, and minimum) were calculated for each region and $R_{\mathrm{rs}}$ wavelength.

\subsection{Diurnal Variability Ocean Color Products}

The differences between VIIRS orbit 1 and orbit 2 were calculated for the chlorophyll-a (CHL; $\mathrm{OC}^{41}$ ), total backscattering at $551 \mathrm{~nm}\left[b_{b} 551 \text {; quasianalytical algorithm (QAA) }\right]^{42}$, and satellite penetration optical depth for several examples and for the comparison/matchup dates. The satellite penetration depth is estimated as the first optical depth, ${ }^{43}$ which is determined as 1 divided by the diffuse attenuation coefficient ${ }^{43-46}$ at $486 \mathrm{~nm}\left(\mathrm{QAA}^{42}\right)$. This closing section provides insight on the potential uses and products that can be generated by looking at the differences between VIIRS orbits. These orbital differences were used to study oceanic fronts, water mass advection, bloom formation/intensification and decay, and changes in the optical depth, which could potentially be used to observe vertical and horizontal movements of these blooms and optical layers in the water column.

\section{Results}

\subsection{Aerosol Robotic Network-Visual Infrared Imaging Radiometer Suite Overlap Comparison}

Figure 3 shows a comparison between WaveCIS data collected throughout the day and VIIRS diurnal variability from two orbits during three different dates: October 11, 2014 [Figs. 3(a)-3(c)], December 9, 2014 [Figs. 3(d)-3(f)], and December 25, 2014 [Figs. 3(g)-3(i)]. The images at the top [Figs. 3(a), 3(d), and 3(g)] represent the difference between chlorophyll-a from VIIRS orbit 1 minus orbit 2. The blue colors represent an increase/bloom (negative difference), and the red colors represent a decrease/decay (positive values) in the chlorophyll-a. 


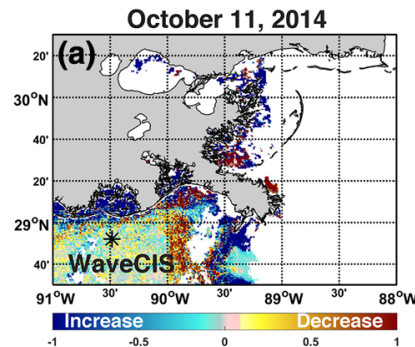

Chlorophyll-a difference $(\mathrm{mg} / \mathrm{m} 3)$
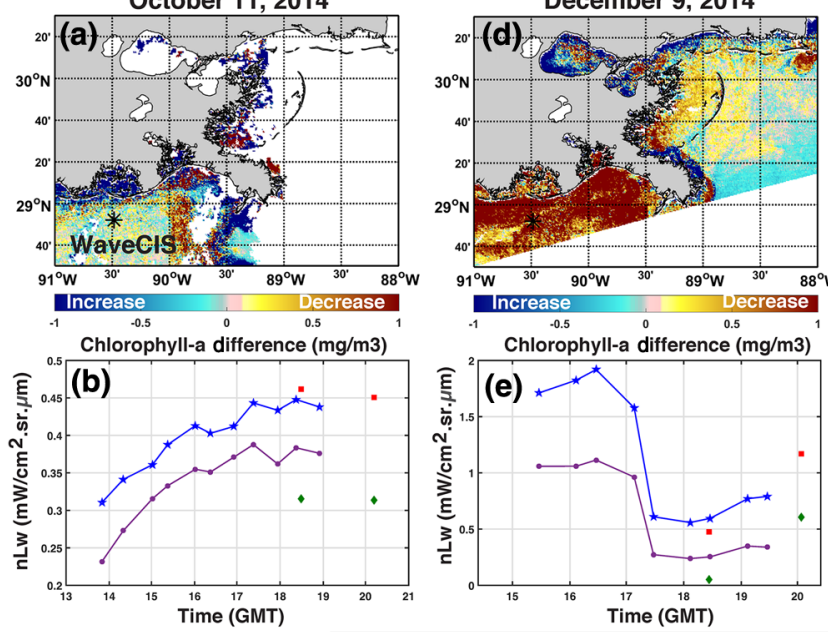

Chlorophyll-a difference $(\mathrm{mg} / \mathrm{m} 3)$
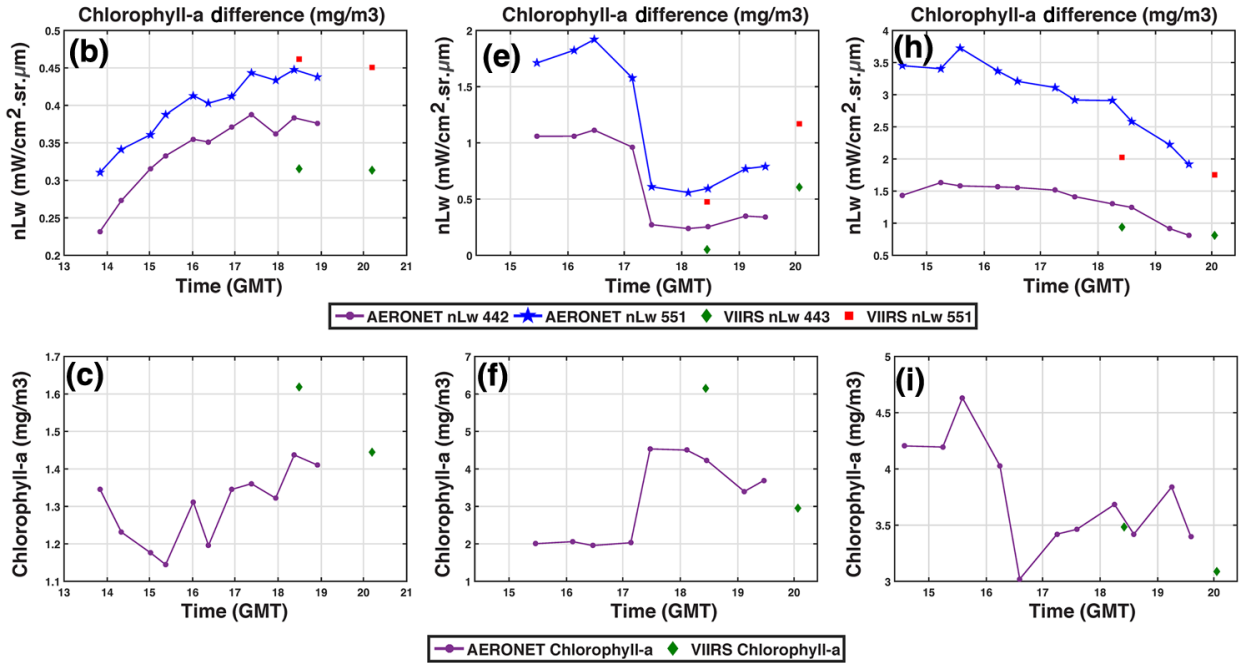

Fig. 3 Matchups between VIIRS and WaveCIS for October 11, 2014 (a-c), December 9, 2014 (d-f), and December 25, 2014 (g-i). The top figures (a, d, g) represent the VIIRS chl-a difference between orbit 1 and orbit 2 . Note the location of WaveCIS site (star symbol). The blue colors represent an increase in chl-a, whereas the red colors represent a decrease. The middle figures (b, e, h) show the WaveCIS $n L_{w} 442$ (purple line) and $n L_{w} 551$ (blue line), and VIIRS $n L_{w} 443$ (green diamonds), and $n L_{w} 551$ (red squares) at the location of the WaveCIS station for each date. The bottom figures (c, f, i) represent the WaveCIS chl-a (purple line) and the VIIRS chl-a (green diamonds) at the location of the WaveCIS station for each date.

The middle plots in Figs. 3(b), 3(e), and 3(h) represent the $n L_{\mathrm{w}} 442$ (purple line) and $n L_{\mathrm{w}} 551$ (blue line) measured for the same day at the WaveCIS station. The corresponding VIIRS values for $n L_{\mathrm{w}}$ at 443 and $n L_{\mathrm{w}}$ at $551 \mathrm{~nm}$ were plotted with the WaveCIS data (green diamonds and red squares) for both orbits. The bottom plots [Figs. 3(c), 3(f), and 3(i)] represent the chlorophyll-a at the WaveCIS station (purple line) and the VIIRS chlorophyll-a for both orbits (green diamonds) computed from spectral $n L_{\mathrm{w}}{ }^{41}$

The VIIRS chlorophyll-a difference between orbits (103-min overlap) on October 11, 2015, was not as variable near the WaveCIS station [Fig. 3(a)]. On October 11, 2015, in situ $n L_{\mathrm{w}} 443$ and $n L_{\mathrm{w}} 551 \mathrm{~nm}$ at the WaveCIS site increased by $50 \%$ continually during the day from 14:00 to 18:00 and then leveled off [Fig. 3(b)]. The VIIRS $n L_{\mathrm{w}}$ matchup for this period showed a similar level trend of the $n L_{\mathrm{w}} 443$ and $551 \mathrm{~nm}$ for orbit 1 and orbit 2 after 18:00 GMT, but the $n L_{\mathrm{w}} 443$ was lower than WaveCIS. The chlorophyll-a [Fig. 3(c)] showed changing trends at WaveCIS during the day with an increase/bloom later in the day. The VIIRS chlorophyll-a from the two orbits was slightly higher but showed similar diurnal variability that occurs for WaveCIS-derived chlorophyll-a.

On December 9, 2014, the VIIRS chlorophyll-a difference ( 97 - min overlap) shows a drastic decrease/decay in the chlorophyll-a around the WaveCIS station [Fig. 3(d), red colors]. Also, the $n L_{\mathrm{w}} 442$ and $n L_{\mathrm{w}} 551$ collected at the WaveCIS station decreased more than half (e.g., $n L_{\mathrm{w}}$ 551: $\sim 1.6$ to $4 \mu \mathrm{W} \mathrm{cm} \mathrm{cm}^{-2} \mathrm{sr}^{-1}$ ) from $\sim 17: 00$ to $\sim 17: 45$ GMT [Fig. 3(e)]. After 18:00 GMT, $n L_{\mathrm{w}}$ began to slightly increase and that is also observed in the VIIRS $n L_{\mathrm{w}}$ orbit 1 and orbit 2 data [Fig. 3(e)]. The WaveCIS station shows a highly variable chlorophyll-a [Fig. 3(f)] during that day with a drastic increase/bloom in the chlorophyll-a from 2 to $4.4 \mathrm{mg} \mathrm{m}^{3}$ in less than an hour 
(17:00 to 18:00 GMT). After 18:00 GMT, chlorophyll-a began to decrease/decay at the WaveCIS site, and the VIIRS chlorophyll-a shows a similar decrease in orbit 2 data.

On December 25, 2014, the VIIRS chlorophyll-a difference ( 97 -min overlap) shows a decrease/decay in the chlorophyll-a around the WaveCIS station [Fig. 3(g), yellow colors]. Similar to December 9, 2014, a steady decrease/decay of $\sim 40 \%$ in $n L_{\mathrm{w}} 443$ and $n L_{\mathrm{w}} 551$ from morning (14:38 GMT) to afternoon (19:00 GMT) was observed on December 25, 2014 [Fig. 3(h)]. The VIIRS $n L_{\mathrm{w}} 443$ and $n L_{\mathrm{w}} 551$ also show a decreasing trend in orbit 2. Chlorophyll-a decreased/decayed from $\sim 4.6$ to $3.0 \mathrm{mg} \mathrm{m}^{3}$ in less than an hour ( $\sim 15: 30$ to 16:30 GMT) at the WaveCIS station [Fig. 3(i)]. After 17:00 GMT, chlorophyll-a was highly variable at the WaveCIS site. The VIIRS chlorophyll-a from orbit 2 shows the decreasing/ decaying trend of the WaveCIS site.

\subsection{Diurnal Changes Across a Transect}

To evaluate the temporal accuracy for the VIIRS ocean color satellite to retrieve ocean color products between the orbital overlap imagery (Figs. 2 and 4), we evaluated the influence of the changes across the sensor zenith angles that occur between the consecutive orbits, by examining along a transect line across east and west angular swaths from $\sim 55$ deg to 70 deg sensor

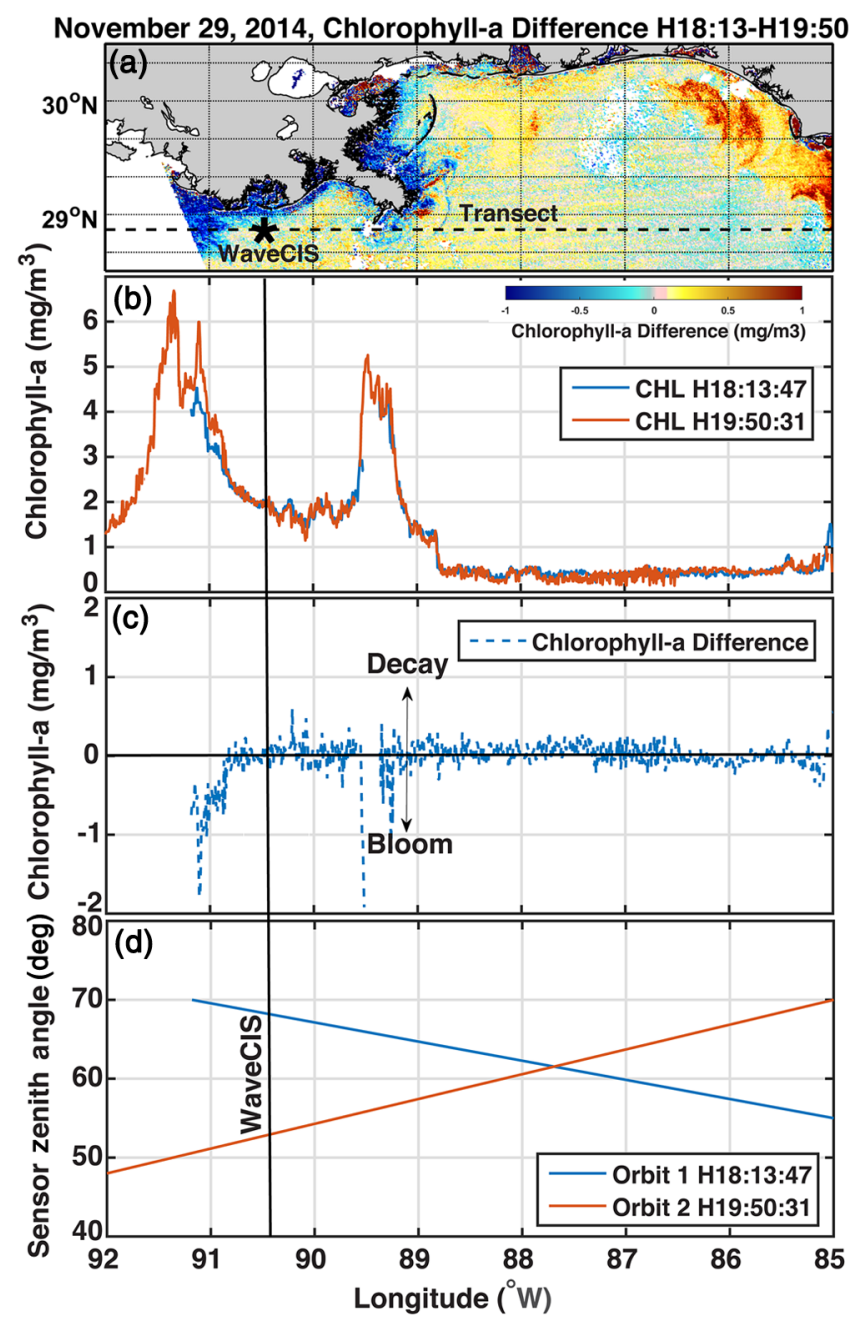

Fig. 4 (a) VIIRS chl-a difference between orbit 1 and orbit 2. Dotted line represents the transect line, where VIIRS data were extracted for both orbits. The transect crossed the WaveCIS station. (b) VIIRS chl-a along transect for orbit 1 (blue line) and orbit 2 (orange line). (c) VIIRS chl-a difference along transect (orbit 1 to orbit 2). (d) Solar zenith angles along transect for orbit 1 (blue line) and orbit 2 (orange line). 
zenith angle for each orbit. At the overlap regions, the sensor zenith angles from nadir on November 29, 2014, for orbit 1 (18:13:47 GMT) were westward, and for orbit 2 (19:50:31 GMT), the angles were eastward. The location of the east-west transect line crossed the WaveCIS station at $28.867^{\circ} \mathrm{N}$, the Mississippi River plume, and several coastal fronts that describe a large range in chlorophyll-a values.

Figure 4(a) shows the difference in chlorophyll-a between VIIRS orbit 1 and orbit 2 ( $\sim 97$ - min overlap). At the WaveCIS station, the chlorophyll-a decreased $\sim 0.5 \mathrm{mg} \mathrm{m}^{-3}$. However, some interesting patterns are observed for the entire region. For example, an increase in chlorophyll-a is observed in coastal areas near the Mississippi discharge region and a decrease is observed offshore the Florida Panhandle region [Fig. 4(a)]. The chlorophyll-a values across the transect line [Fig. 4(b)] show similar patterns in orbit 1 (blue line) and orbit 2 (orange line). The difference between orbit 1 and orbit 2 chlorophyll-a along the transect line [Fig. 4(c)] was relatively consistent. Negative chlorophyll-a differences were observed near the regions with high river discharge, representing an increase in chlorophyll-a during the second orbit. In offshore waters between $88.5^{\circ} \mathrm{W}$ and $85.5^{\circ} \mathrm{W}$, the chlorophyll-a differences were near zero [Fig. 4(c)]. The sensor zenith angle for orbit 1 (blue line) and orbit 2 (orange line) along the transect line showed the changes in the overlap region ranging from $50 \mathrm{deg}$ to $70 \mathrm{deg}$ [Fig. 4(d)]. At $87.5^{\circ} \mathrm{W}$, both orbits had the same zenith angle of $61 \mathrm{deg}$ [Fig. 4(d)].

Figure 5(a) shows the $R_{\mathrm{rs}} 443$ and $R_{\mathrm{rs}} 551$ for both orbits. They both show similar patterns, and the difference is near zero for most locations except near the Mississippi plume discharge region [Fig. 5(b)]. A very small east-west linear decreasing trend is observed in the $R_{\mathrm{rs}} 443$ and $R_{\mathrm{rs}} 551$ difference [Fig. 5(b)]. This small trend could possibly be related to the sensor view angle;
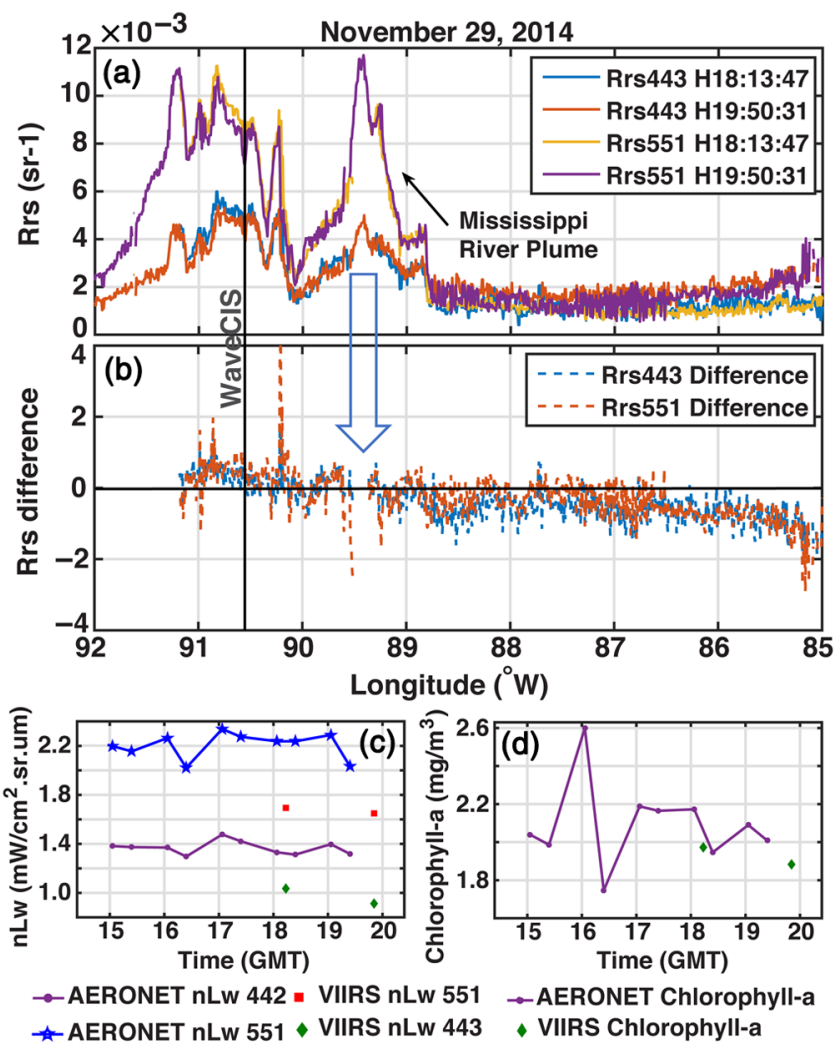

Fig. 5 VIIRS and WaveCIS data for November 29, 2014. See transect line in Fig. 4(a). (a) Along the transect VIIRS: $R_{\mathrm{rs}} 443$ for orbit 1 (blue line), $R_{\mathrm{rs}} 443$ for orbit 2 (orange line), $R_{\mathrm{rs}} 551$ for orbit 1 (yellow line), $R_{\mathrm{rs}} 551$ for orbit 2 (purple line). (b) VIIRS difference (orbit 1 to orbit 2) for $R_{\mathrm{rs}} 443$ (blue line) and $R_{\mathrm{rs}} 551$ for orbit 2 (orange line). (c) WaveCIS $n L_{\mathrm{w}} 442$ (purple line) and $n L_{\mathrm{w}} 551$ (blue line), and VIIRS $n L_{w} 443$ (green diamonds) and $n L_{w} 551$ (red squares) at the location of the WaveCIS station. (d) WaveCIS chl-a (purple line) and the VIIRS chl-a (green diamonds) at the location of the WaveCIS station. 
however, we could not observe this trend in the other images that were analyzed nor in the chlorophyll-a. $R_{\mathrm{rs}} 551$ [Fig. 5(b), orange line] shows the highest differences near the Mississippi discharge, which is possibly due to the movement of particles associated with the plume front. The differences in the orbital zenith angles [Fig. 4(b)] across the east-west transect line ranged $\pm 20 \mathrm{deg}$. Even though the orbital zenith angle differs so much across the transect line, the diurnal differences in the $R_{\mathrm{rs}}$ or chlorophyll-a are near zero. This indicates that the diurnal differences observed in the VIIRS ocean color $\left(R_{\mathrm{rs}}\right)$ are not correlated with the sensor zenith angle differences, and ocean color satellite processing is handling the sensor look angle correctly to determine the normalized remote sensing reflectance and $R_{\mathrm{rs}}$. The transect line crossed the WaveCIS [Figs. 4(a), 5(c), and 5(d)]. The WaveCIS $n L_{\mathrm{w}}$ and chlorophyll-a diurnal changes from 15:00 to 19:20 GMT were relatively consistent. The VIIRS $n L_{\mathrm{w}}$ and chlorophyll-a showed similar trends in the temporal response compared with WaveCIS. Transects across the coastal zone have shown similar diurnal response compared with the WaveCIS site. Sometimes significant diurnal variability occurs, and other times, they are consistent. This suggests that the different processes such as movement of coastal ocean color water masses are affecting the ocean color response and that the color signatures are changing.

\subsection{Cruise Data and Visual Infrared Imaging Radiometer Suite Matchups}

During the NASA GEOCAPE on September 12, 2013, cruise stations (A and B) were collected in Louisiana coastal waters (Fig. 6) during VIIRS orbital overlaps. The VIIRS orbit 1 was at 18:10:49 GMT and orbit 2 was at 19:53:14 GMT for an $\sim 103$-mn difference. The spectral $R_{\mathrm{rs}}$ matchup of the five VIIRS channels at these locations with both the in situ and VIIRS orbit 1 and orbit 2 are shown in Fig. 6. At station A1 [Fig. 6(A1); 15:30 GMT], the in situ $R_{\mathrm{rs}}$ data matched well with the data obtained by earlier VIIRS orbit 1, which was $2 \mathrm{~h}$ later. At station A2 [Fig. 6(A2); 18:35 GMT], the in situ data were closest to the later orbit 2. The differences between the in situ and VIIRS $R_{\mathrm{rs}}$ is higher toward the higher wavelengths (e.g., $676 \mathrm{~nm}$ ). A similar pattern is observed for stations B1 [Fig. 6(B1); 19:34] and B2 [Fig. 6(B2); 19:57 GMT], where the first station matches orbit 1 and the second station matches orbit 2 . At both stations $\mathrm{A}$ and $\mathrm{B}$, a change in the temporal difference between stations was observed, which was similar to the temporal difference in the VIIRS ocean color. The uncertainty in the matchup may be due to a larger time difference between in situ and stations and the spatial variability in the diurnal cycle of ocean color. This indicates that to validate ocean color $\left(R_{\mathrm{rs}}\right)$ with in situ observations, the timing between matchups should be closer because diurnal changes can be significant in coastal regions, leading to higher uncertainty. The percent spectral uncertainty [Fig. 6(A2)] at station A between the VIIRS 103- min orbits ranged from $4 \%$ at $410 \mathrm{~nm}$ to $31 \%$ at $671 \mathrm{~nm}$. The uncertainty between in situ $R_{\mathrm{rs}}$ matchups with VIIRS is dependent on the degree of diurnal changes that occur between orbits. Satellite validation requires the matchups to be $<1 \mathrm{~h}$ (within $30 \mathrm{~min}$ ) apart in highly varying coastal locations.

Figures 6(c) and 6(d) show a matchup comparison of the in situ and VIIRS total backscattering at $440\left(b_{b} 440\right) \mathrm{nm}$ and total absorption at $486 \mathrm{~nm}$ (a486) for the three stations (A1, A2, and A3) for orbit 1 and orbit 2 . The one-to-one line shows that the in situ $b_{b} 443$ is lower than both VIIRS overlaps. The a486 in situ was lower than the VIIRS overlap for orbit 1 and closer to the VIIRS data for orbit 2. The best matchup of backscattering and absorption occurs when the in situ (station A2) and VIIRS orbit 1 were closest (18:35 and 18:10 GMT) and confirms the timing of $<1$ hour for validation. The percent difference between both VIIRS orbits for $b_{b} 440$ and a486 ranged between $18 \%$ and $35 \%$. These differences between the in situ stations and the VIIRS overlap could be associated with diurnal changes in the diurnal bio-optical processes, which can occur within 103 min.

Diurnal changes in ocean color were also observed on April 3, 2016 in the coastal waters of Mobile Bay during the CONCORDE spring cruise (Fig. 7). The $R_{\mathrm{rs}}$ diurnal changes at five spectral channels between the two overlap orbits [Figs. 7(a) and 7(b); 17:56:07 and 19:38:33 GMT] were determined for four stations [Fig. 7(c)]. $R_{\mathrm{rs}}$ was highest at station 1 and decreased toward station 4 for both VIIRS and in situ data [Fig. 7(d)]. Stations 1 and 4 had the highest temporal variability between the two VIIRS orbits, whereas stations 2 and 3 had lower ocean color changes between the 102-min orbits overlaps. The diurnal changes in VIIRS 


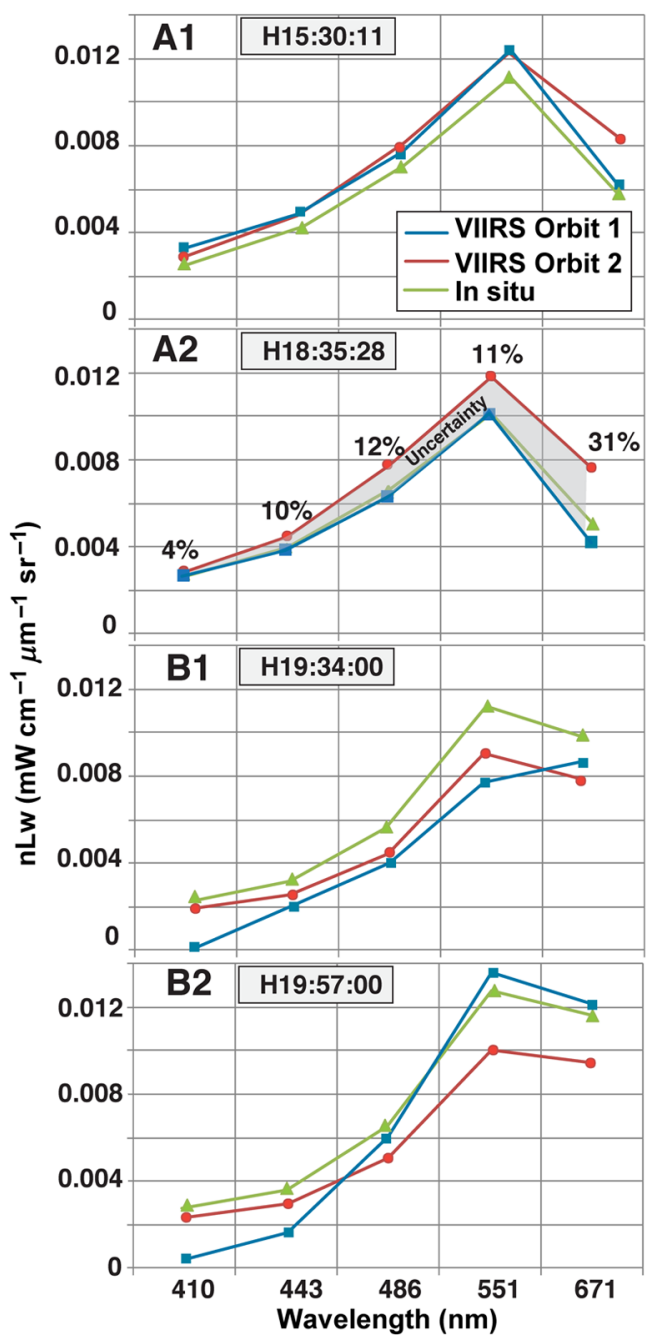

September 12, 2013
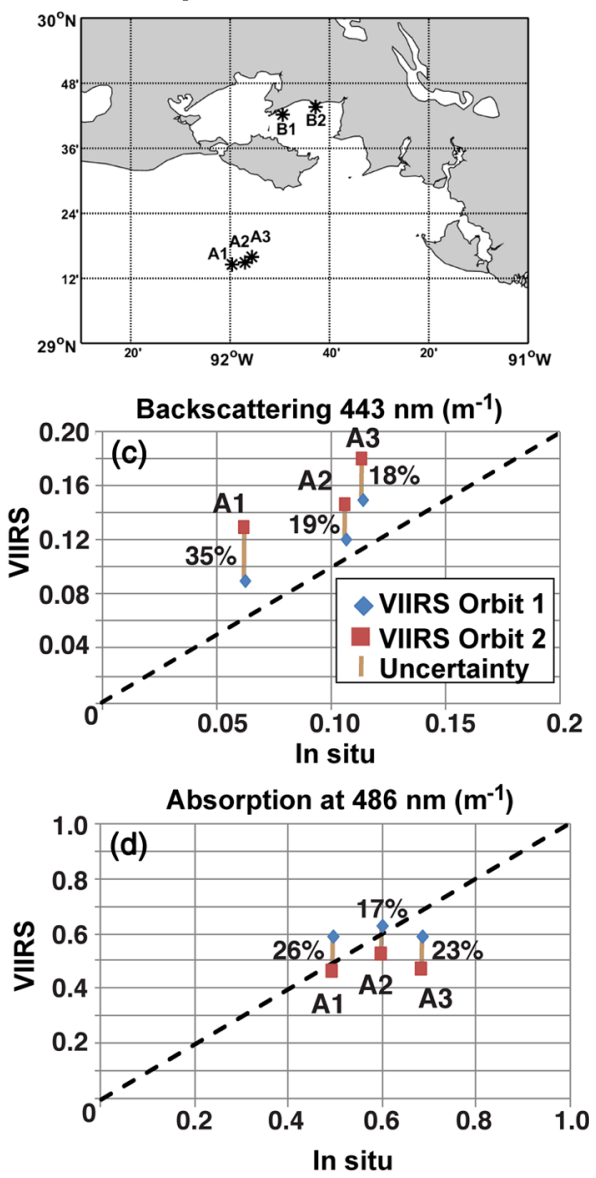

Fig. 6 Map on the right shows the GEOCAPE stations off the coast of southern Louisiana. Plots of the spectral in situ $n L_{w}$ (blue line) and VIIRS $n L_{w}$ from orbit 1 (18:10, red line) and orbit 2 (19:53, green line) on September 12, 2013, at stations A1 (15:30), A2 (18:35 GMT), B1 (19:34 GMT), and B2 (19:57 GMT). The shaded blue color on plot A2 represents the percent spectral $n L_{w}$ uncertainty of the VIIRS overlap and in situ $n L_{w}$. (c) Matchup of in situ and VIIRS backscattering at $443 \mathrm{~nm}$, and (d) absorption at $486 \mathrm{~nm}$ at stations A1, A2, and A3 with percent diurnal changes in VIIRS overlaps.

chlorophyll-a concentration at each station [Fig. 7(e)] showed a decrease of $15 \%$ at stations 4 and 3 , an increase of $3 \%$ at station 2 , and no changes $(<0.3 \%)$ at station 1 . This indicates that temporal changes are spatially varying in response to different processes.

The percent diurnal spectral changes between orbits at each station are shown in the table inside Fig. 7(f). The largest percent of change occurred for $R_{\mathrm{rs}} 671$ at station 4 . The average percent diurnal change in $R_{\mathrm{rs}}$ at these four stations varied from $3.73 \%$ at $410 \mathrm{~nm}, 6.5 \%$ at $443 \mathrm{~nm}, 5.99 \%$ at $486 \mathrm{~nm}, 5.89 \%$ at $551 \mathrm{~nm}$, and $13.21 \%$ at $671 \mathrm{~nm}$. The average percent chlorophyll-a change was $8.03 \%$ at these stations. Longer time periods throughout the day would possibly show larger percent differences as was shown at the WaveCIS (Fig. 3).

A floating hyperpro measured the inwater $R_{\mathrm{rs}}$ at the four stations from 17:09 to 20:02 GMT. The best agreement between VIIRS and hyperpro inwater $R_{\mathrm{rs}}$ was observed at the closest time to the VIIRS overpass [Fig. 7(d)]. Hyperpro station 4 at 20:02 GMT matched better with orbit 2 at 19:38 GMT (closest in time), and hyperpro station 2 (17:09 GMT) matched better with orbit 1 (closest in time) at 17:56 GMT. This indicates that validation of ocean color requires close timing of less than an hour with the overpass. 

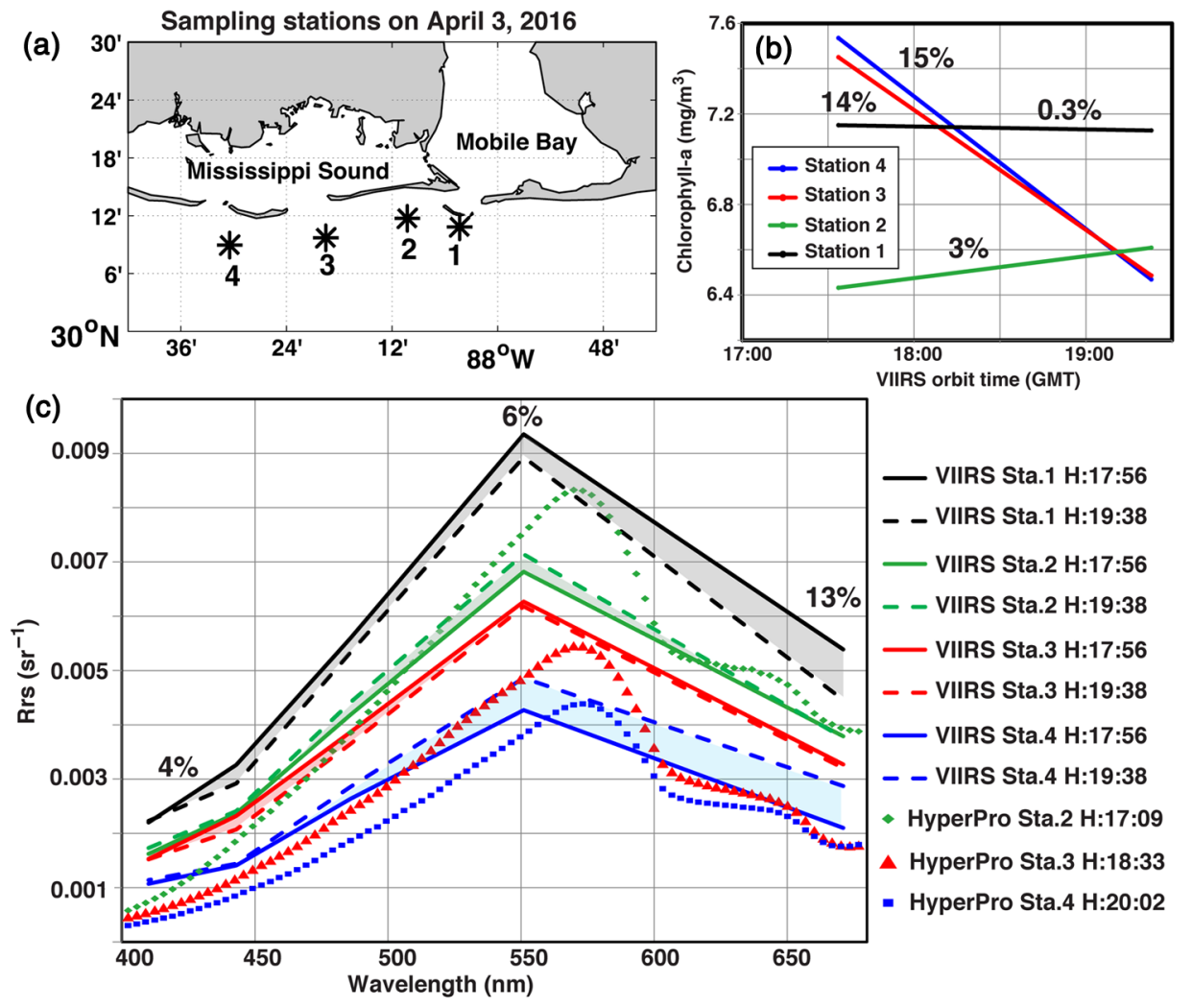

(d) Percent difference between orbits

\begin{tabular}{|c|c|c|c|c|c|c|}
\hline Station & Chlorophyll-a & Rrs 410 & Rrs 443 & Rrs 486 & Rrs 551 & Rrs 671 \\
\hline 1 & 0.33 & 1.35 & 11.00 & 4.75 & 4.60 & 18.88 \\
\hline 2 & 2.71 & 6.57 & 1.67 & 5.34 & 4.58 & 0.79 \\
\hline 3 & 13.84 & 0.66 & 11.39 & 5.85 & 1.45 & 2.16 \\
\hline 4 & 15.23 & 6.33 & 2.11 & 8.00 & 12.92 & 30.99 \\
\hline Average (\%) & 8.03 & 3.73 & 6.54 & 5.99 & 5.89 & 13.21 \\
\hline
\end{tabular}

Fig. 7 (a) CONCORDE sampling stations on April 3, 2016. (b) VIIRS chl-a changes within 102 min for both orbits (H17:56 and 19:28 GMT) at the four sampling stations. The percent of change between orbit 1 and orbit 2 is annotated within the figure. (c) Plot of spectral $R_{\mathrm{rs}}$ at stations 1 to 4 from the two VIIRS orbits and floating inwater hyperspectral measurements (hyperpro). (d) Table of the percent changes of chl-a and $R_{\mathrm{rs}}$ between both VIIRS orbits at all the stations and the average.

\subsection{Seasonality in the Ocean Color Diurnal Variability}

The diurnal changes observed in individual scenes were examined to see how the hourly ocean color changed throughout a seasonal cycle. How did the diurnal changes in ocean color change throughout the year? First, we compared monthly means of $n L_{\mathrm{w}} 551$ collected at the WaveCIS station versus VIIRS and MODIS-aqua means (Fig. 8) for 2014. Figure 8 shows data for days in which the WaveCIS station returned above eight radiance matchups for 1 day, and there was concurrent data from VIIRS overlap and MODIS-aqua. The red and blue bars represent the monthly $n L_{\mathrm{w}} 551$ average of the three satellite overpasses (VIIRS + MODIS) and WaveCIS, respectively, with the standard deviation. The difference between the means of two sensors reflects bias, error and subpixel variation, and diurnal variability. The matchup between the satellite data and the WaveCIS was good throughout the seasons and indicates that diurnal changes from VIIRS/MODIS and WaveCIS occur throughout the year.

We next addressed the question of whether the diurnal color changes throughout the year were dependent on different water types. For each month in 2014 (January to October), the 


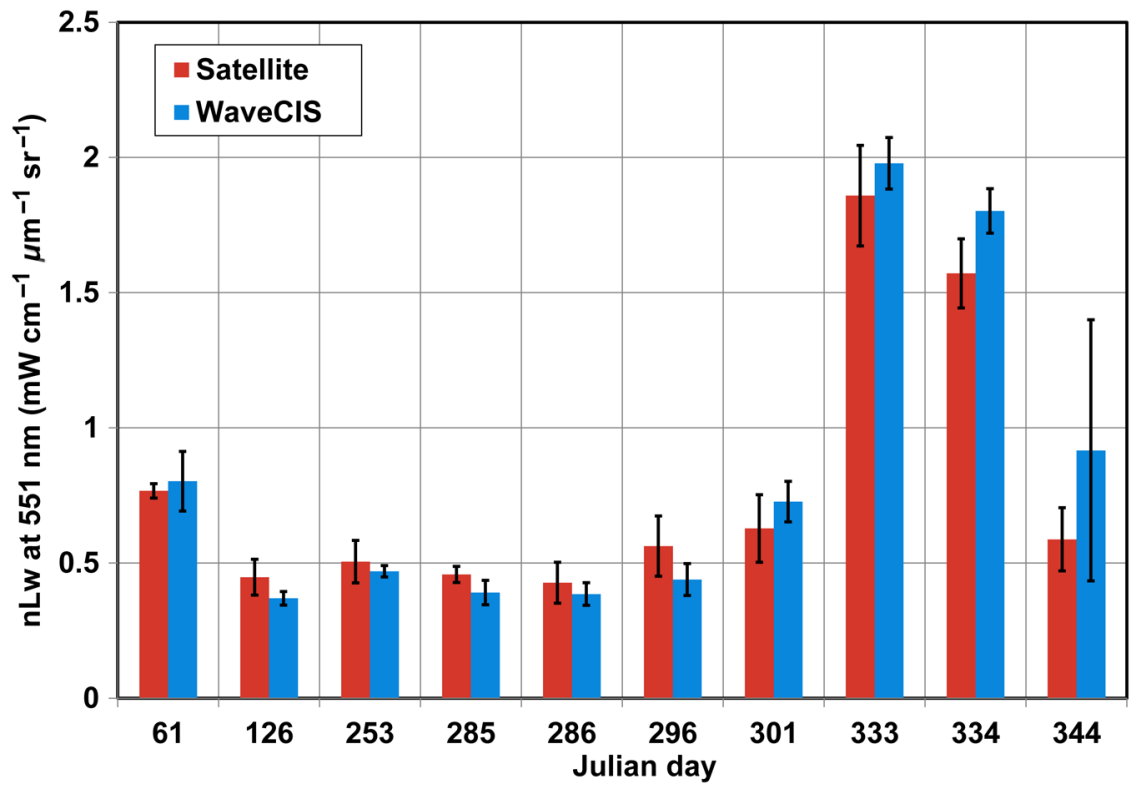

Fig. 8 Time series from WaveCIS station in 2014, showing days with 8 to 11 WaveCIS measurements, matched up with the average of satellite measurements (VIIRS overlaps) and MODIS, from the same day. The error bars represent the standard deviation, which may be interpreted as the satellite in situ uncertainty in conjunction with diurnal changes.

statistics of the spectral $R_{\mathrm{rS}}$ of VIIRS spectral channels for the three regions representing different water types (a) open ocean, (b) shelf, and (c) coastal, shown in Fig. 1, was determined for each VIIRS overlap orbit. For each month, one cloud-free VIIRS diurnal imagery was selected. A table and figure are included in the Appendix, showing the total number of pixels per month for each water type used in this analysis as well as an example of the statistical analysis. The regional statistics (mean, maximum, minimum, and standard deviation) for each spectral channel was calculated for each month. Using these regional statistics for each region and water mass for each month, the mean diurnal $R_{\mathrm{rs}}$ difference for orbit 1 minus orbit 2 was determined for each water type for each month [Figs. 9(a)-9(d)]. Each subplot in Fig. 9 represents a specific VIIRS spectral channel (410, 443, 551, and $671 \mathrm{~nm}$ ). Positive $R_{\mathrm{rs}}$ difference indicates that $R_{\mathrm{rs}}$ decreased from orbit 1 to orbit 2 , and negative $R_{\mathrm{rs}}$ values represent an increase in $R_{\mathrm{rs}}$ with the second orbit. This shows what time of day the $R_{\mathrm{rs}}$ values are higher through the months for the different water masses. The largest monthly diurnal differences in the orbits occurred in $R_{\mathrm{rs}} 410 \mathrm{~nm}$. Coastal waters showed the highest positive diurnal $R_{\mathrm{rs}} 410$ difference in January, September, and October and lowest difference from April to June. Interestingly, coastal waters had negative differences for almost all spectral channels in the month of February. Open oceanic waters had higher positive $R_{\mathrm{rs}}$ differences (decrease in $R_{\mathrm{rs}}$ from orbit 1 to orbit 2) in October and January, while having negative differences most of the other months. Fall and winter (October and January) showed that the first orbit had a higher $R_{\mathrm{rs}}$, whereas in the summer (June, July, and August), the second orbit showed a higher $R_{\mathrm{rs}}$. This change in orbital timing of $R_{\mathrm{rs}}$ could be related to the daily solar elevation effect on ocean color, which also changes throughout the year. The time of overpass for the orbits is generally consistent ( $\sim 18: 00$ and 19:00 GMT) throughout the year, therefore, the differences observed in $R_{\mathrm{rs}}$ could be related to the monthly solar elevation changes. For example, solar elevation is higher at hour 19:00 GMT than 18:00 GMT during the summer months than in winter months. This effect is observed in the VIIRS 410-nm spectral channel, especially in open waters [Fig. 9(a), blue bar] as a negative $R_{\mathrm{rs}}$ difference in the summer months (see June) and positive difference during the winter months (see January and October). Coastal waters had a higher positive difference during the month of March for $R_{\mathrm{rS}} 443$ to $R_{\mathrm{rs}} 551$, and $R_{\mathrm{rs}} 671$ showed the lowest differences among all the VIIRS channels (Fig. 9). 


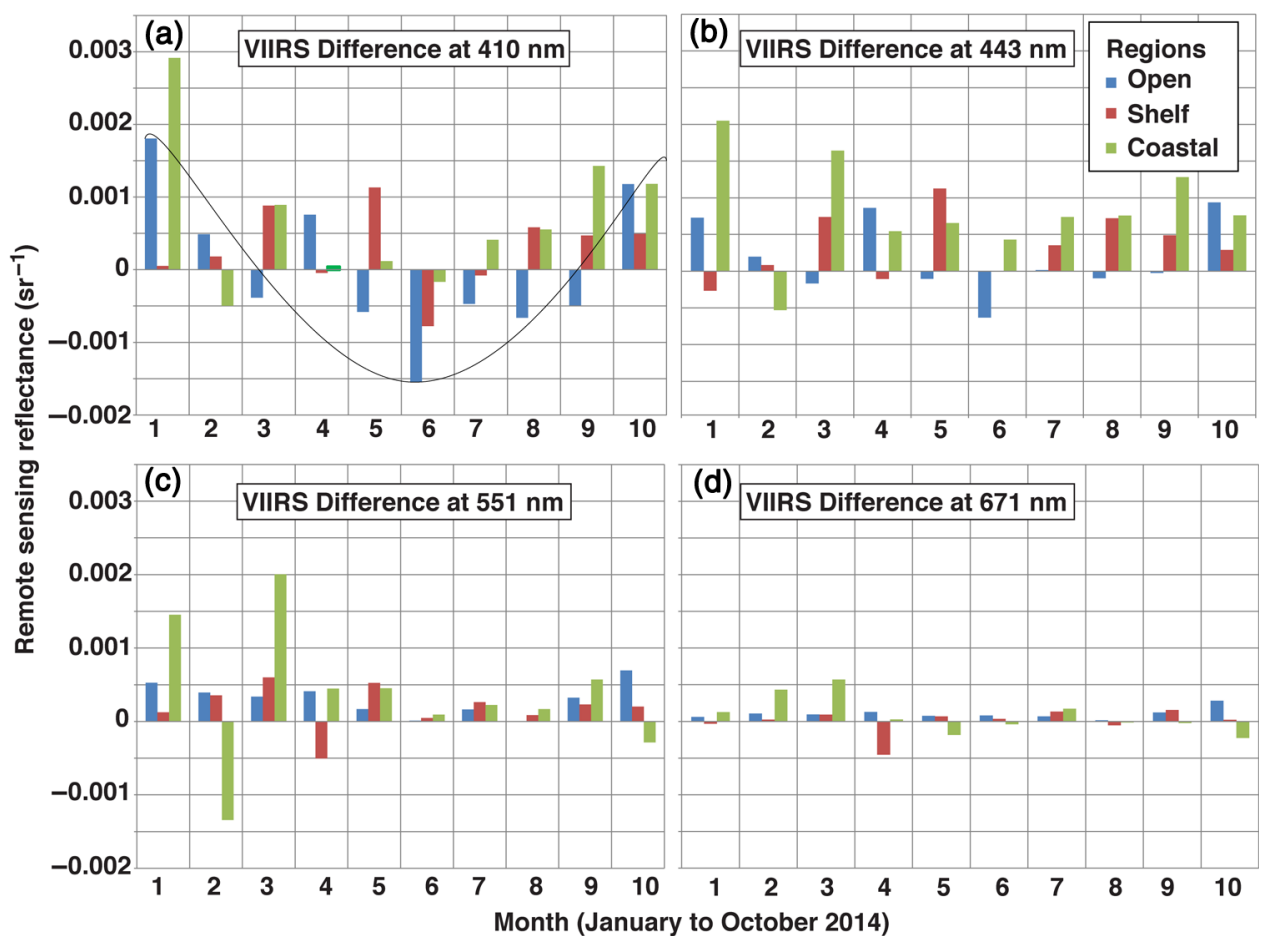

Fig. 9 The monthly average diurnal difference (orbit 1 to orbit 2) in $n L_{w}$ for VIIRS spectral channels: (a) $410 \mathrm{~nm}$, (b) $443 \mathrm{~nm}$, (c) $551 \mathrm{~nm}$, and (d) $671 \mathrm{~nm}$ at three different regions within the Gulf of Mexico regions representing open, shelf, and coastal waters. See boxes in Fig. 1 for location of these regions. The line in (a) helps visualize the decreasing trend in the diurnal difference during the summer months from higher solar elevation in the second orbit.

\subsection{Diurnal Ocean Color Products}

In this section, we show potential applications of calculating the ocean color differences between the VIIRS orbit 1 and orbit 2. The first example was using the overpasses (orbit 1: 17:56 and orbit 2: 19:38) for April 3, 2016, for chlorophyll-a (Fig. 10).The April 3, 2016, chlorophyll-a product [Figs. 10(a) and 10(b)] shows the Mobile Bay river plume moving westward onto the shelf. The differences between orbit 1 minus orbit 2 for chlorophyll-a, total backscattering at $551 \mathrm{~nm}$, and optical depth was calculated for April 3, 2016. The chlorophyll-a difference product [Fig. 10(c)] represents a change within the water masses and not just frontal movements or water mass advection, which is increasing in concentration from orbit 1 to orbit 2. East of the Chandelier islands (arrow) there is an elongated region showing a water mass that is characterized by a diurnal increase in chlorophyll-a of $\sim 2 \mathrm{mg} \mathrm{m}^{-3}$. Negative difference values suggest that subsurface optical layers of phytoplankton may be moving toward the surface layer showing an increase in surface chlorophyll-a within the 102-min overlap. Along the inshore Mississippi Sound and Mobile Bay, there was a substantial increase in chlorophyll-a ( $>3 \mathrm{mg} \mathrm{m}^{-3}$ blue colors). These waters are influenced by wind mixing and tides, which can affect the movement of the optical layers in surface waters and the corresponding color changes.

The diurnal change in total backscattering 551 [Figs. 11(a)-11(c)] has different features compared with the chlorophyll-a difference. The change in scattering from particle concentration can be related to particle advection, settling, and/or resuspension in the surface layer. The backscattering difference product [Fig. 11(c)] showed a particle increase in the west side of the Mobile Bay river plume [see arrow in Fig. 11(c); blue colors] and a particle decrease on the eastern side of the plume, which may be related to westward advection of the plume. The backscattering changes within the river plume could be related to changes in the location of the plume and horizontal and vertical distribution of the plume layers and sediment settling. In the Mississippi Sound, the different backscattering values may be related to particle resuspension (blue colors) and settling (yellow colors). 

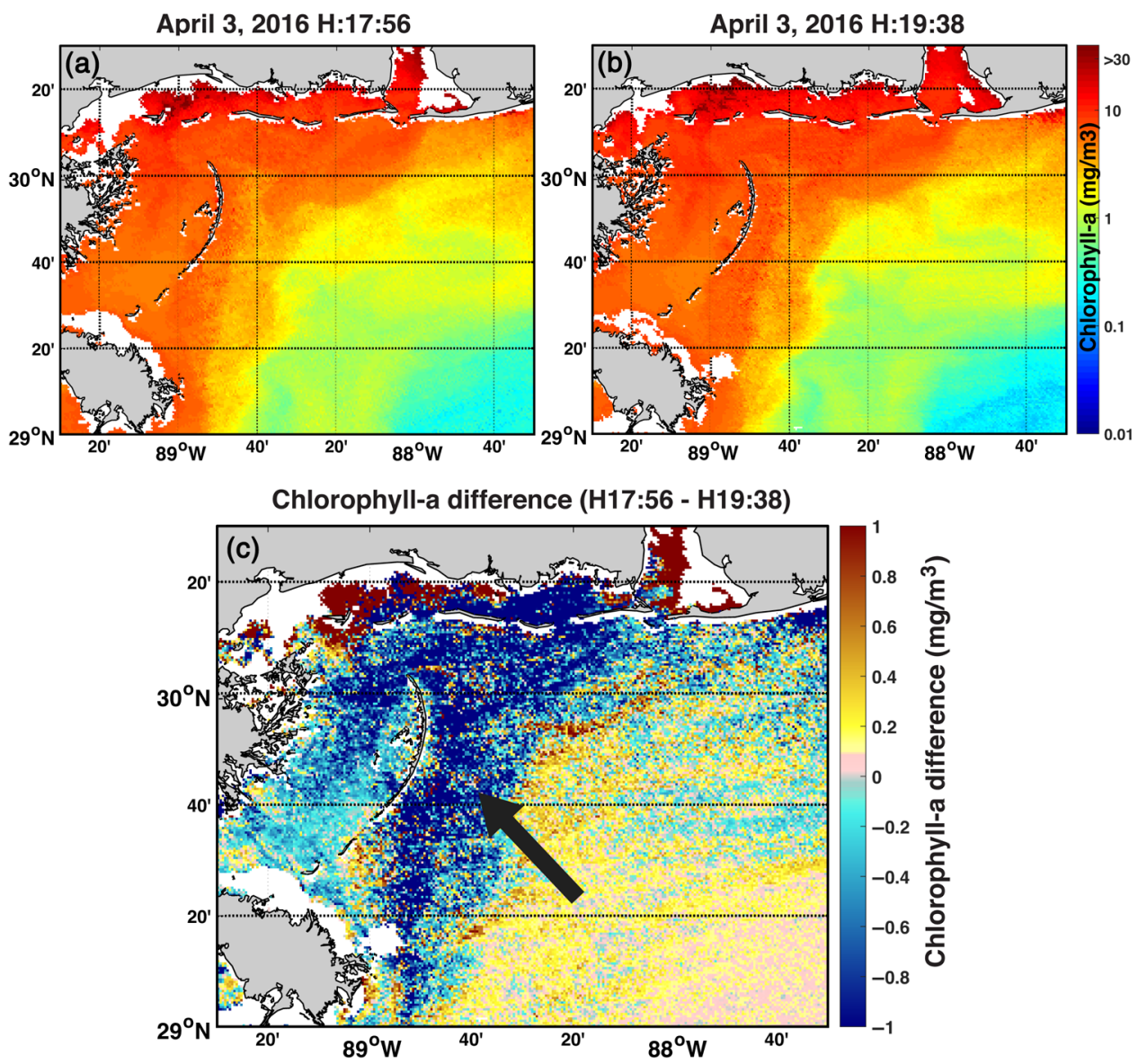

Fig. 10 VIIRS imagery for April 3, 2016. (a) chl-a orbit 1 (17:56 GMT). (b) chl-a orbit 2 (19:38 GMT). (c) chl-a difference between orbit 1 and orbit 2. Negative (blue) values indicate a diurnal increase or possible bloom.

The ocean color can change as subsurface optical layers move into the first optical depth, which is sensed by the satellite. The satellite optical penetration depth determined as one over the diffuse attenuation coefficient at $486 \mathrm{~nm}$ from the QAA algorithm ${ }^{42}$ is shown for each of the overlapping orbits [Figs. 12(a)-12(c)]. ${ }^{43-46}$ The satellite optical penetration depth represents the vertical extent to which the ocean color satellite is detected. ${ }^{43}$ The difference of optical depths (orbit 1 minus orbit 2) can represent the changes in the depth the satellite is sensing. This depth change may represent vertical movement of subsurface optical layers between the 102-min period orbits. The spatial changes in the optical depth for April 3, 2016 [Fig. 12(c)] suggest locations of upwelling (positive values: red colors) and downwelling (negative values: blue colors) within the time period.

Vertical movement of phytoplankton layers has been shown to change during the day, which can impact the ocean color. ${ }^{7,8,15}$ The changes in color can be representative of the vertical movements, which can vary with different processes and phytoplankton layers. Studies have shown vertical migration of Karenia brevis layers during the day within the first 5-m and peaking at the surface around hour 16:00 local time affects ocean color. ${ }^{8,9}$ These regions of diurnal changes in satellite optical penetration depth from the color response can represent vertical movements of these optical layers, which can have a response to the locations of the diurnal chlorophyll-a increase (bloom) and decrease (decay). The same location east of the Chandelier Islands with an increase in chlorophyll-a [Fig. 10(c); see arrow] showed a positive satellite optical penetration depth difference [Fig. 12(c)], indicating upwelling of waters with higher chlorophyll or possibly vertical migration of phytoplankton layer into the satellite penetration depth. Regions of negative difference in penetration optical depth (blue colors) identify water mass regions with 

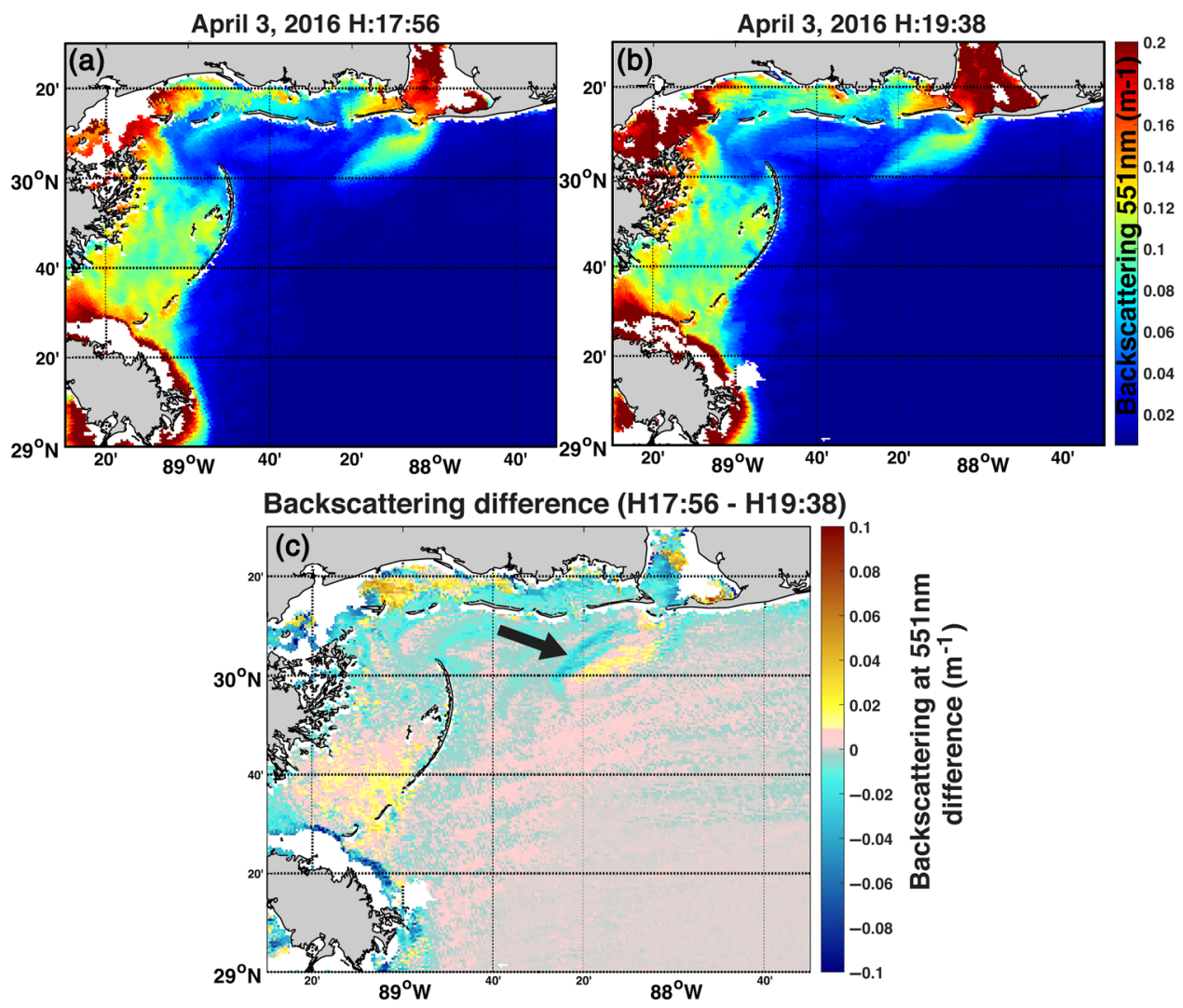

Fig. 11 VIIRS imagery for April 3, 2016. (a) Backscattering at $551 \mathrm{~nm}$ orbit 1 (17:56 GMT). (b) Backscattering at $551 \mathrm{~nm}$ orbit 2 (19:38 GMT). (c) Backscattering at $551 \mathrm{~nm}$ difference between orbit 1 and orbit 2 . Negative values indicate diurnal particle increase.

reduced change in diurnal chlorophyll-a between orbits and possibly deepening of subsurface layers.

The spatial features of these vertical water mass movements shown as the differences in penetration optical depth in Fig. 12 appear to be representative of ocean features representing cross shelf exchange processes on the Mississippi shelf. ${ }^{13,47}$ Coastal waters east of the Chandelier Islands and south of the Mississippi Sound show regional positive differences in optical penetration depths.

The location and shape of the different features observed in the ocean color difference products (chlorophyll-a, backscattering, and optical penetration depth) do not show a decreasing trend from east to west and are generally circular patches or filaments indicating that they are unrelated to the satellite sensor or solar angles.

The diurnal differences from the satellite in the chlorophyll, backscattering, optical penetration depth (Figs. 10-12) do not show similar ocean features or patterns, even though all these products are derived using the satellite water-leaving radiances. Each ocean product represents a validated algorithm, and the diurnal difference products represent the change in the optical property and not necessarily the water-leaving radiance. Therefore, the spatial variability in each product is representative of ocean processes which affect the individual optical property. The dissimilarity in ocean features between these diurnal products (Figs. 10-12) also supports that products are not affected by satellite sensor angle and validates satellite processing. Features changes in each diurnal product can represent different processes.

Another example of spatial diurnal products (Fig. 13) illustrates water mass changes and the advection of oceanic fronts using the chlorophyll-a difference between orbit 1 (18:13 GMT) and orbit 2 (19:50 GMT) for November 29, 2014. The chlorophyll-a images from orbit 1 [Fig. 13(a)] and orbit 2 [Fig. 13(b)] appear very similar; however, the chlorophyll difference (orbit 1 from orbit 2) shows the location of a localized decrease in chlorophyll-a indicating a possibly diurnal "decay" on the Mississippi shelf [Fig. 13(c)]. This decay region is nonlinear or aligned with the 

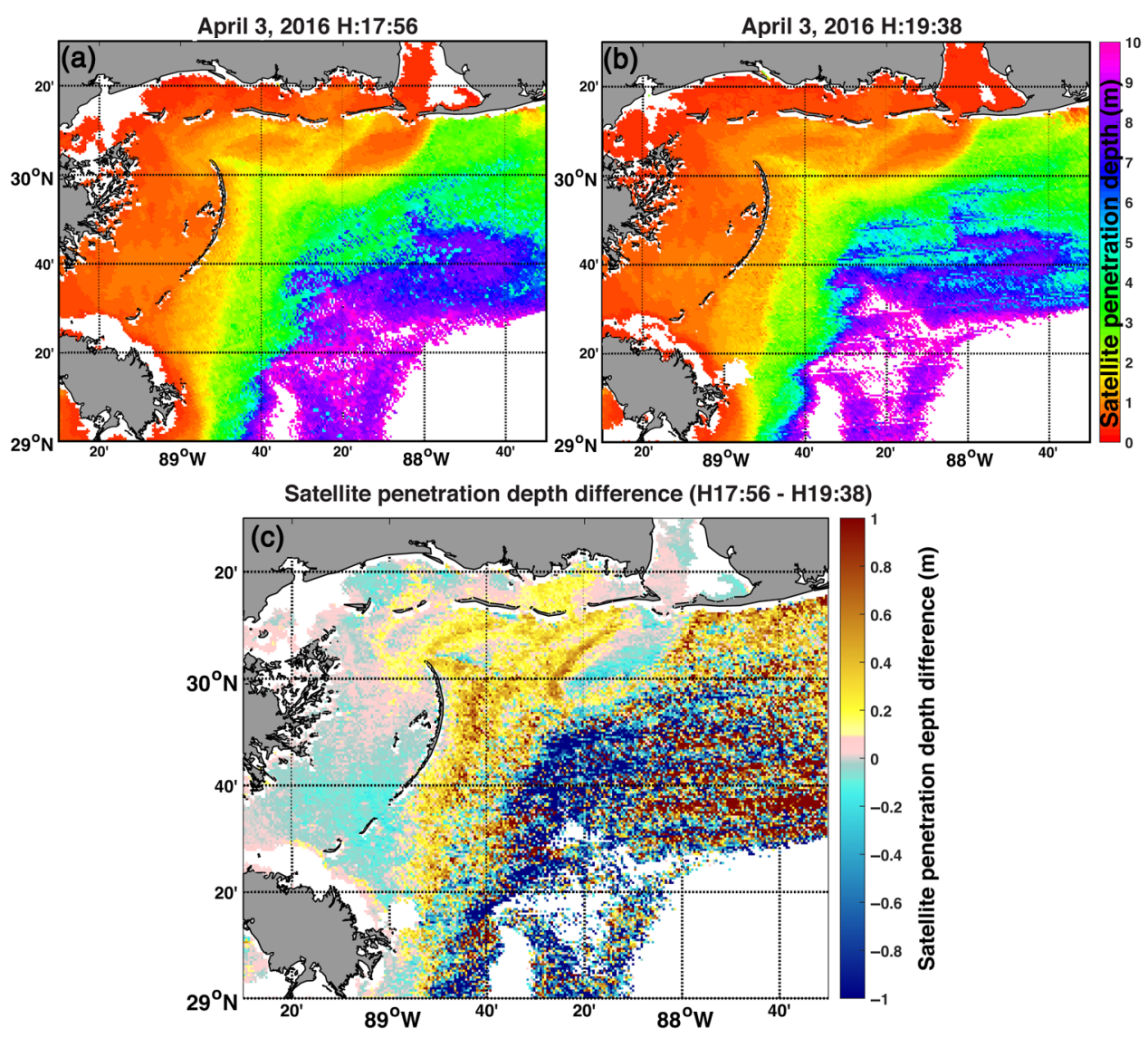

Fig. 12 VIIRS imagery for April 3, 2016. Satellite optical penetration depth at $486 \mathrm{~nm}$ (a) orbit 1 (17:56 GMT) and (b) orbit 2 (19:38 GMT). (c) Difference in the satellite optical penetration depth at $486 \mathrm{~nm}$ between orbit 1 and orbit 2 . Negative values indicate the depth of diurnal vertical deepening and positive values a rising of subsurface layers.

east-west difference in the satellite sensor looking angle. Areas to the east and west of the decay area are not decaying linearly; therefore, these waters [Fig. 13(c)] represent a diurnal color change that is not related to sensor or sun angles. This decay region was not observed in other images, for example, Fig. 10, indicating that these diurnal changes are spatial and temporal variables. Note that the far east of Fig. 13(c) has areas of minimal difference (pink colors) even though those are areas with a higher sensor zenith angle. Therefore, the products represent the effect of diurnal ocean color changes on different water masses.

The location of ocean color frontal movement or water mass advection is also observed in the chlorophyll-a difference image [Fig. 13(d); zoom]. A Mississippi River plume front is shown as an elongated feature of decreased chlorophyll (blue) in the difference product indicating the front is moving westward at $\sim 0.6$ knots within the 97-min overlap. Water mass advection features appear more linear representing frontal movements that are different from bio-optical water mass differences, the latter of which are dispersive as shown in the decaying region [Fig. 13(c)]. The rapid temporal color change that can occur at ocean fronts confirms the importance that validation of satellite products with in situ matchup data at frontal regions and demonstrates a minimum time constraint requirement of $<60 \mathrm{~min}$ in rapid water mass movement areas.

These types of diurnal color changes occurring in surface waters associated with water mass advection can be used to estimate surface currents. ${ }^{48}$ There are certain ocean color properties that can be associated with water mass advection processes rather than bio-optical processes. Figure 14 shows how the use of changing ocean color products from the diurnal VIIRS orbital overlaps can be used to estimate surface currents using the maximum cross correlation (MCC) method. ${ }^{49}$ MCC is based on determining similarity in spatial gradients for each orbit between each ocean color product and was used to estimate surface currents. The surface currents for each 

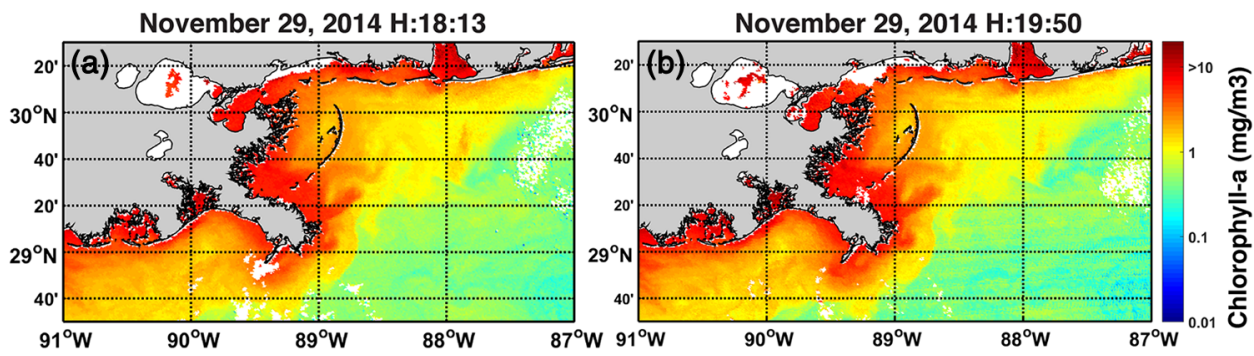

Chlorophyll-a difference (H18:13 - H19:50)
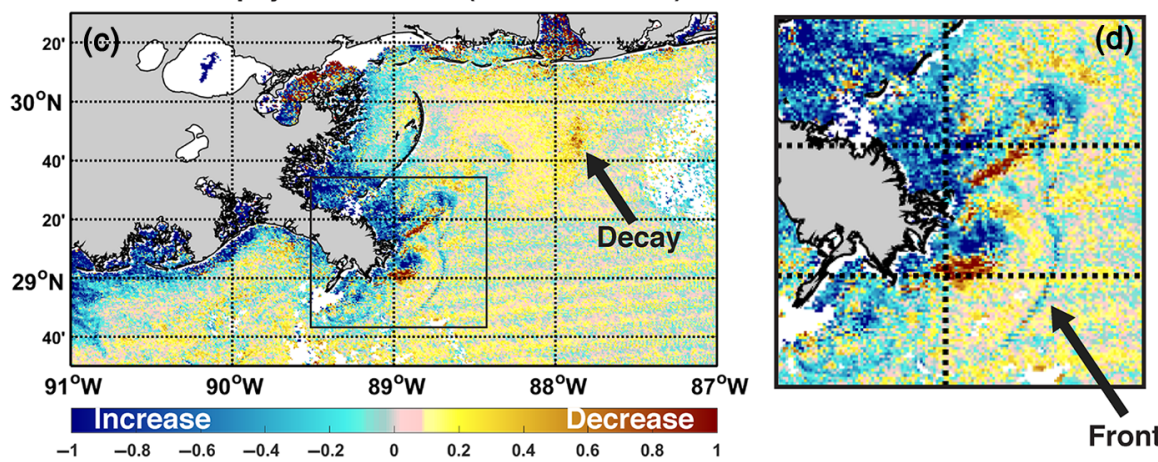

Chlorophyll-a difference $(\mathrm{mg} / \mathrm{m} 3)$

Fig. 13 VIIRS imagery for November 29, 2014. (a) chl-a orbit 1 (18:13 GMT). (b) chl-a orbit 2 (19:50 GMT). (c) chl-a difference between orbit 1 and orbit 2. Negative values indicate that values for orbit 2 are higher than orbit 1, which is diurnal increase. Positive values show region of degrading chl-a. (d) Zoom in of the chl-a difference to show a linear oceanic frontal movement.
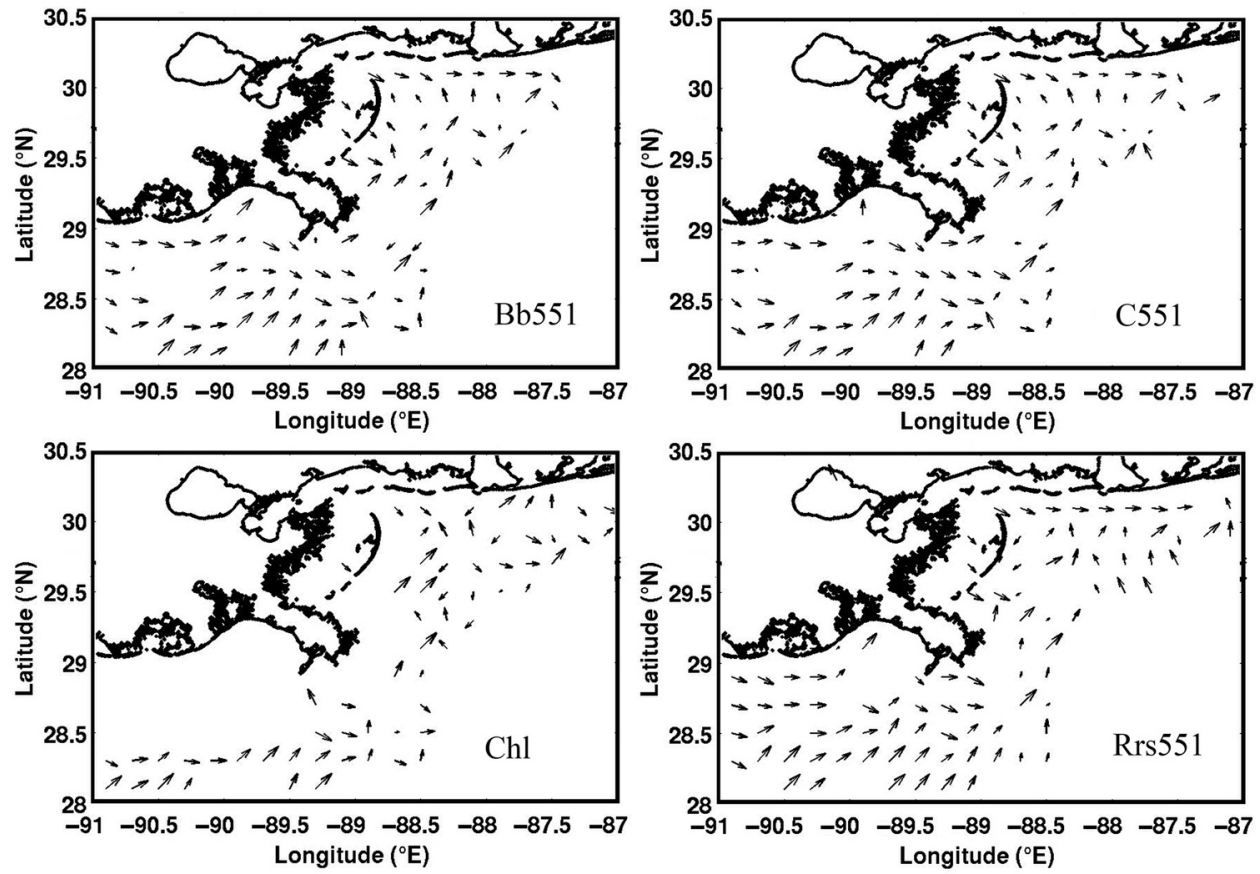

Fig. 14 Diurnal changes from VIIRS overlaps in ocean color can be used to estimate surface currents using MCC from these four different color products. Each product shows different number of retrieved surface current vectors. ${ }^{48}$ 
color product are determined based on the movement of a spatial gradient from one orbit to next. Currents are constrained by the maximum distance a water mass can move within the 100-min period between orbits and currents are computed, provided MCC constraints are met. Four different ocean color products: total backscattering at $551 \mathrm{~nm}$, chlorophyll-a, beam attenuation at $551 \mathrm{~nm}$, and $R_{\mathrm{rs}} 551 \mathrm{~nm}$ from the VIIRS diurnal overlap were used to generate the surface currents using the MCC method (Fig. 14). Certain ocean products, such as $\mathrm{b}_{\mathrm{b}} 551$ and $R_{\mathrm{rs}} 551$, were capable of retrieving more surface currents with MCC than other products, which indicates that these products may be more closely related to advection processes of water masses from diurnal changes than diurnal bio-optics changes, such as the chlorophyll-a product. ${ }^{48}$

\section{Discussion}

Changes in ocean color occurring during hourly diurnal variability throughout the day have been shown by the WaveCIS station in the northern Gulf of Mexico. The color changes were not consistent throughout all days but were highly variable in response to dynamic coastal processes and subsurface optical layers. Rapid color changes were shown to occur at WaveCIS as high as $40 \%$ within a 60 -min period. The consecutive orbital overlaps of the VIIRS ocean color sensor showed changes in ocean color within $100 \mathrm{~min}$ in the coastal zone of the northern Gulf of Mexico. Using the same VIIRS sensor for overlap supports intersatellite consistency to remove uncertainty between intersensor characterization and calibration. The changes in ocean color within 100 min between the VIIRS overlaps were confirmed and verified by the WaveCIS station and in situ observations to follow the diurnal trends of both the $n L_{\mathrm{w}}\left(R_{\mathrm{rs}}\right)$ and the derived biooptical products.

The matchup of $n L_{\mathrm{w}}$ for VIIRS and WaveCIS on October 11, 2014 [Figs. 3(a)-3(c)] for the corresponding time periods shows a decreasing $n L_{\mathrm{w}}$ trend seen at the WaveCIS site, with a higher level of uncertainty later in the day in orbit 2 . The satellite matchup uncertainties are possibly related to (1) the spatial variability of the VIIRS satellite coverage of $\sim 1500 \mathrm{~m}$ (at high zenith angles) ground resolution (pixel size) compared with the measurement at the WaveCIS site and (2) corrections for sensor and solar angles including the water bidirectional reflectance distribution function (BRDF) ${ }^{50}$ for the high angles in orbital overlap.

The WaveCIS matchups for December 9 and December 25, 2014, of the ocean color products $\left(n L_{\mathrm{w}}\right.$ and chlorophyll-a) from VIIRS overlaps, and MODIS clearly shows a close relationship and the trend of the diurnal cycle at WaveCIS [Figs. 3(d)-3(i)]. This example clearly shows that differences between the satellite overpass for this locations may be real and not be an inconsistency issue with individual sensors characteristics. The matchup with the diurnal changes observed from WavCIS are better for December 9, 2014 [Figs. 3(d)-3(f)] than October 11, 2014 [Figs. 3(a)-3(c)]. This could be due to the processing for sensor solar angles, BRDF, and atmospheric correction for VIIRS orbits.

The uncertainty of the spectral changes that occur in ocean color orbital overlaps was shown to range from $4 \%$ to $31 \%$ changing with time and space. These changes in ocean color can occur in dynamic coastal areas and in response to water mass advective processes and bio-optical changes in depth of optical layers. Similar changes in the surface reflectance have been shown for diurnal changes in the surface expression of harmful algal blooms due to phytoplankton vertical migration. $8,9,51$

The impact of different satellite sensor and solar angles and the impact on the retrieved ocean color were examined to confirm the VIIRS overlaps are capable of retrieving the hourly changes in ocean color (Figs. 4 and 5). Different levels of uncertainty between ocean color satellite and in situ matchups were shown indicating that diurnal variability in ocean color can change in time and space. Sensor angles would have an east to west effect on the atmospheric correction and the diurnal variability. However, the spatial variability in the diurnal change products is observed in both the north-south and east-west directions, and suggests that these diurnal change products are valid and not obstructed by the east-west sensor angles.

Matchups of in situ and orbital overlaps of VIIRS overlaps show the uncertainty that can occur with the 100-min periods in coastal areas. Matchups that are closer to the overpass time are better especially in coastal waters. These temporal changes must be considered when 
validating and calibrating ocean color sensors in coastal areas because of the dynamic nature of the color signatures.

Diurnal processes that can cause a chlorophyll-a change include upwelling and downwelling of optical layers into the first optical depth, which result in enhanced and decreased surface pigments from surface color. Movement of ocean color water masses can be used to determine surface currents. Certain color products $\left(b_{\mathrm{b}} 550\right.$ and $\left.R_{\mathrm{rs}} 551\right)$ respond better to water mass advection for producing surface currents using maximum cross-correlation between multiple hourly/ overlap images than others color products (i.e., chlorophyll-a). Diurnal color changes can improve identifying bio-physical processes between satellite products and circulation models. ${ }^{3}$

Diurnal changes in ocean color due to vertical migration of phytoplankton blooms have also been shown using GOCI data that have sequential imagery from morning to afternoon. ${ }^{51}$ Diurnal changes ocean color products have been used to show how the intensity of phytoplankton blooms change throughout the day and to understand the vertical migration patterns. ${ }^{8,9}$ The GOCI diurnal change products have shown an increase of $124 \%$ in the surface reflectance from 09:30 to 14:30 local time, ${ }^{51}$ which is larger than the 100-min diurnal VIIRS overlap changes. The time of the peak of algal bloom reflectance occurs close to the time of VIIRS overpasses, but this could change with seasons.

The monthly diurnal difference in VIIRS spectral channels was examined throughout the seasons in 2014. Three water masses (open ocean, shelf, and coastal waters) have different diurnal changes. During some months, the first orbit has the highest spectral $R_{\mathrm{rs}}$, and for the other months, the second orbit was the highest. Shelf waters are highly variable through the season but still have diurnal differences. These diurnal changes can be related to the solar intensity during the daily cycle, which is stronger in summer and the response of the biological optical layers to the surface solar levels. Migration of biological layers to the surface layer may occur at different times during the day depending on the daily surface light levels. This overpass time of the orbit during the daily cycle is shown to impact the spectral response of the ocean color signature. The processes that affect the diurnal changes in different water masses can be variable and they need to be further investigated.

$R_{\mathrm{rs}} 551$ showed a decrease in the monthly diurnal $R_{\mathrm{rs}}$ compared with $R_{\mathrm{rs}} 410$. The largest diurnal changes occurred in coastal waters in January, February, and March in similar patterns as $R_{\mathrm{rs}} 410$. The monthly variability in the diurnal changes in the ocean color $\left(R_{\mathrm{rs}}\right)$ is different for the three water masses and indicates that the ocean color products generated from these spectral ocean colors will be different depending on the time of the overpass for different months. These analyses demonstrated that the diurnal difference in water color changes throughout the year and suggests that there are certain months when the earlier orbit has greater $R_{\mathrm{rs}}$ than the second orbit and certain months when this is reversed for different water types.

The features that are observed in these diurnal chlorophyll difference products are similar to the ocean plume and eddy features and not merely related to solar or sensor zenith angles. The diurnal changes appear related to the bio-optical structure and physical processes of the water masses and do not appear related to inaccuracies in the ocean color processing.

\section{Conclusions}

Ocean color can change rapidly throughout the day especially in coastal areas where dynamic ocean processes occur. ${ }^{1}$ Our objective was to examine the diurnal changes in ocean color that can occur in coastal regions and determine the capability of the present polar orbiting satellites to identify and validate these changes. Results confirm that satellite ocean color can provide a unique capability to capture diurnal changes in ocean color especially in coastal areas. The rapidly changing ocean color signatures can provide new tools for monitoring diurnal processes in the coastal zone and support the requirements for a geostationary ocean color satellite. The diurnal changes in ocean color identify the limitations of current ocean color polar orbiters data collection to their single time of orbital overpass, which may not be the optimum time for different water masses and seasons. The present study confirms that the diurnal variability with the VIIRS afternoon orbits was significant. However, larger diurnal changes throughout the day from morning to late afternoon are expected as shown at the WaveCIS site and by GOCI 
imagery. ${ }^{51}$ The ability for multiple ocean color measurements throughout the day from a geostationary satellite will provide significant improvement to defining the wide ranging diurnal changes in ocean color and improve characterization of the surface bio-optical processes.

Using the same time of overpass for a polar orbital sensor throughout the year does not account for changes in ocean color throughout the day, which can occur for different water types. Ocean color products from current polar orbiters (VIIRS and MODIS) with a single afternoon overpass times does not account for the seasonal diurnal changes (solar elevation changes) that are shown. Although the diurnal cycle of ocean color is shown to change through the seasons using the average of three different water masses (open, shelf, and coastal): the optimal time for the orbital overpass for data collection will change depending on the season and different water mass to provide the highest or representative $R_{\mathrm{rs}}$ color levels. The changes in the peak reflectance time during the day can be related to the physical and biological processes (such as particle resuspension, plankton vertical migration, and/or displacement of optical layers).

The diurnal ocean color cycle can provide methods to better define average daily biological concentration and the vertical response of phytoplankton pigments to solar light levels and physical processes. The changes in diurnal water quality ocean color products (chlorophyll-a, backscattering, and optical penetration depth) are shown to occur repeatedly throughout different ocean waters for each of the different products, and these diurnal changes can provide a new science tool to improved characterization of surface ocean conditions with respect to defining long-term (climate) changes.

This paper provides insight about the potential of satellite ocean color to determine rapid changes in ocean color during the day and opens up new areas for future research. New ocean products can be developed based on diurnal changes for each ocean color property to characterize spatial variability of surface diurnal processes and movement of bio-optical layers within the water column. Hourly changes in ocean color can be used for defining both the physical processes, such as water mass advection or surface currents and biological optical processes. Chlorophyll-a differences within the 100-min VIIRS overlaps show areas of potential blooms (increase) and decay (decrease). Diurnal changes in the optical depth between VIIRS orbits identify locations of vertical migration of subsurface layers responding to physical and biological processes. This includes vertical movement of both density layers (such as river plumes) and phytoplankton optical layers in the near-surface water, which can impact the surface water color. ${ }^{9}$ The spatial variability of the diurnal changes ocean color products can provide significant advantage to understanding these near-surface processes. The VIIRS orbit overlap clearly identified a capability to identify changes of bio-optical products occurring within a 100-min overlaps. Larger diurnal changes can be expected by considering longer daily time periods

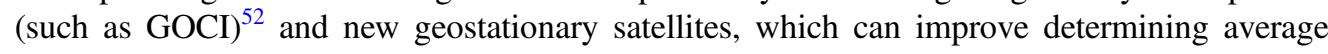
water quality conditions especially in coastal waters.

\section{Appendix: Monthly Diurnal Changes}

The methods used to determine monthly diurnal changes from January to October 2014 in Fig. 9 are summarized. Monthly diurnal $R_{\mathrm{rs}}$ data were assembled for three large regions (shown in Fig. 1) representing different water masses (open, shelf, and coastal waters) using cloud-free coverage for orbit 1 and orbit 2 . The table shows the date of the cloud-free image per month and the number of valid pixels for each region and orbit per month (Fig. 15). These valid number of pixels for orbit for each month and water mass are representative of the diurnal coverage for five spectral channels.

Figure 15 is an example of the statistical analysis. For this purpose, we selected January 19, 2014, and the open ocean region. The first two plots (a and b) show the $R_{\mathrm{rs}}$ histogram of valid pixels for each orbit and each VIIRS channel. The statistical mean $R_{\mathrm{rs}}$ for each orbit and channel [Figs. 15(c) and 15(d)] were used to determine the January open ocean monthly diurnal changes which are shown in Fig. 9 for five VIIRS M1 to M5 channels (412, 443, 486, 551, and 670). A similar analysis procedure was performed for each of the water masses, orbits, and VIIRS channels for each month Fig. 9. 


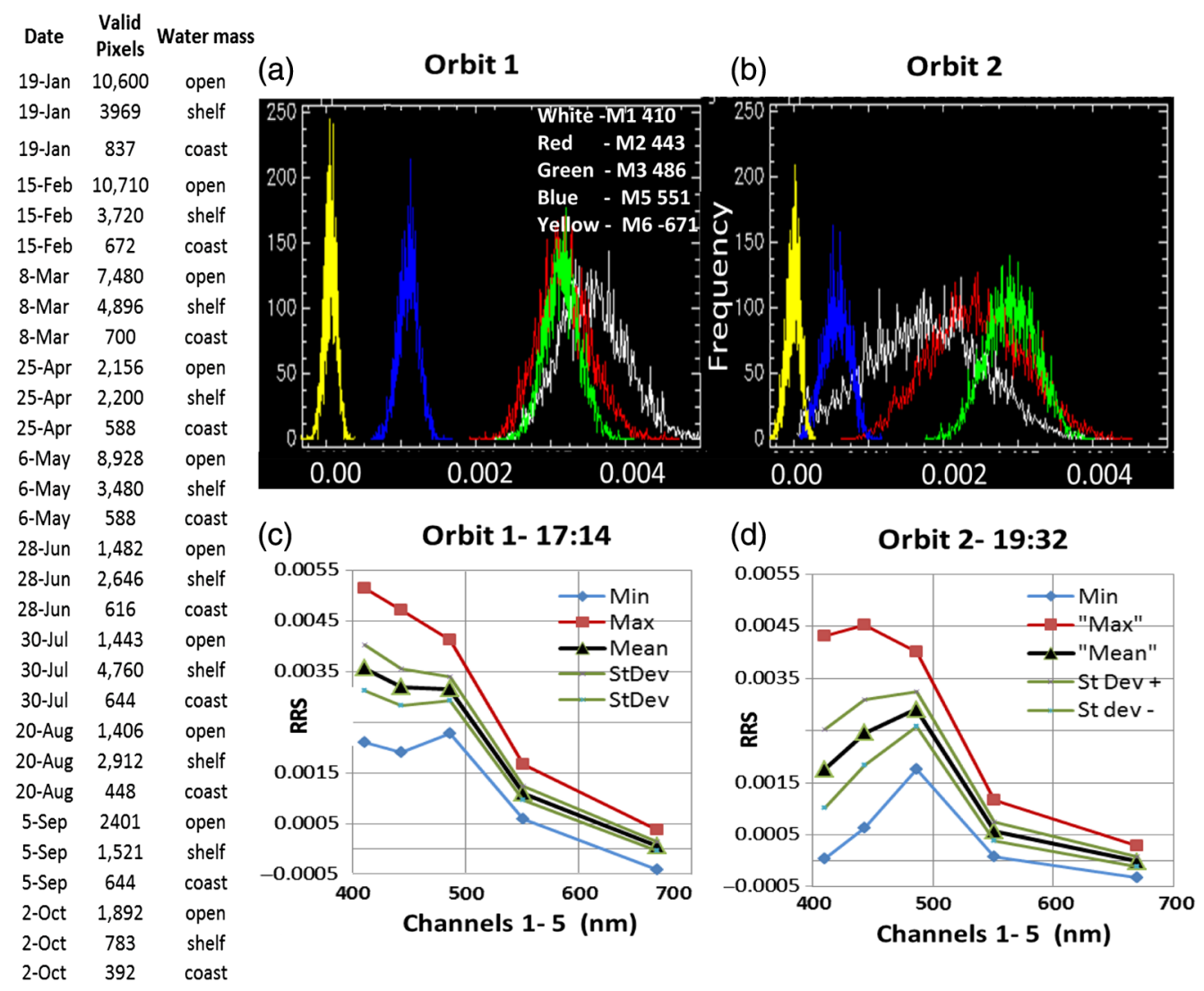

Fig. 15 Example of open ocean region for Jan 19, 2014 of the diurnal change in the VIIRS channels. Similar methods used for all data in the table, and results of the seasonal change shown in Fig. 9.

\section{Acknowledgments}

We acknowledge the NOAA_-JPSS VIIRS Ocean Color Cal/Val Project for VIIRS calibration and grant support. We appreciate NOAA STAR for providing VIIRS data and the JPSS SDR team for contribution of the VIIRS weekly LUTS. We acknowledge the AERONET WaveCIS Site (LSU), Bill Gibson, NOAA, JPSS, and NASA AEONET for data. We appreciate the NASA GEOCAPE program for cruise support and data collection. We appreciate the GOMRI CONCORDE-Coastal River-Dominated Ecosystem program for ship measurements. This research was made possible by grants from NOAA (JPSS), NASA (GEOCAPE) and Gulf of Mexico Research Initiative (GOMRI) programs mentioned above. Data are publicly available through the Gulf of Mexico Research Initiative Information and Data Cooperative (GRIIDC) (doi: 10.7266/N7416V4D and doi: 10.7266/N7XW4GV8). We appreciate the excellent reviewer comments that helped clarify the uncertainty in diurnal changes and identified new areas for research in diurnal ocean color.

\section{References}

1. M. L. Wang et al., "Ocean diurnal variations measured by the Korean geostationary ocean color imager," in Oral presentation, CoRP 9th Annual Science Symp., Madison, Wisconsin (2013).

2. Z. P. Lee et al., "A model for the diffuse attenuation coefficient of downwelling irradiance," J. Geophys. Res. 110, C02016 (2005).

3. R. A. Arnone et al., "Physical and bio-optical processes in the Gulf of Mexico-linking realtime circulation models and satellite bio-optical and SST properties," No. NRL/PP/7330-055226, p. 10, Naval Research Laboratory, Stennis Space Center, Mississippi (2005). 
4. R. Arnone et al., "Chapter 13: examples of IOP applications," in Remote Sensing of Inherent Optical Properties: Fundamentals, Tests of Algorithms, and Applications, Z. P. Lee, Ed., Reports of the International Ocean-Colour Coordinating Group, No. 5, pp. 95-104, IOCCG, Dartmouth, Canada (2006).

5. M. Baeye et al., "Sediment mobility in response to tidal and wind-driven flows along the Belgian inner shelf, southern North Sea," Ocean Dyn. 61, 611-622 (2011).

6. J. Mercado et al., "Diurnal changes in the bio-optical properties of the phytoplankton in the Alboran Sea (Mediterranean Sea)," Estuarine Coastal Shelf Sci. 69(3), 459-470 (2006).

7. W. Durham and R. Stocker, "Thin phytoplankton layers: characteristics, mechanisms, and consequences," Апnи. Rev. Mar. Sci. 4, 177-207 (2012).

8. C. Hu et al., "Vertical migration of Karenia brevis in the northeastern Gulf of Mexico observed from glider measurements," Harmful Algae 58, 59-65 (2016).

9. O. Schofield et al., "Vertical migration of the toxic dinoflagellate Karenia brevis and the impact on ocean optical properties," J. Geophys. Res. 111, C06009 (2006).

10. R. P. Stumpf and M. A. Tyler, "Satellite detection of bloom and pigment distributions in estuaries," Remote Sens. Environ. 24(3), 385-404 (1988).

11. H. M. Sosik et al., "Temporal and vertical variability in optical properties of New England shelf waters during late summer and spring," J. Geophys. Res. 106(C5), 9455-9472 (2001).

12. K. Curran et al., "Settling velocity, effective density, and mass composition of suspended sediment in a coastal bottom boundary layer, Gulf of Lions, France," Cont. Shelf Res. 27, 1408-1421 (2007).

13. F. E. Muller-Karger et al., "On the seasonal phytoplankton concentration and sea surface temperature cycles of the Gulf of Mexico as determined by satellites," J. Geophys. Res. 96(C7), 12645-12665 (1991).

14. N. Takamura and M. Yasuno, "Diurnal changes in the vertical distribution of phytoplankton in hypertrophic Lake Kasumigaura, Japan," Hydrobiologia 112(1), 53-60 (1984).

15. R. A. Arnone et al., "Effects of vertical chlorophyll structure and solar irradiance on remote sensing ocean color spectrum," Proc. SPIE 2258, 322 (1994).

16. S. Hlaing et al., "Evaluation of the VIIRS ocean color monitoring performance in coastal regions," Remote Sens. Environ. 139, 398-414 (2013).

17. J. H. Ryu et al., "Temporal variation in Korean coastal waters using geostationary ocean color imager," J. Coastal Res. SI 64, 1731-1735 (2011).

18. G. Neukermans, K. G. Ruddick, and N. Greenwood, "Diurnal variability of turbidity and light attenuation in the southern North Sea from the SEVIRI geostationary sensor," Remote Sens. Environ. 124, 564-580 (2012).

19. Q. Vanhellemont, G. Neukermans, and K. Ruddick, "Synergy between polar-orbiting and geostationary sensors: remote sensing of the ocean at high spatial and high temporal resolution," Remote Sens. Environ. 146, 49-62 (2014).

20. X. He et al., "Using geostationary satellite ocean color data to map the diurnal dynamics of suspended particulate matter in coastal waters," Remote Sens. Environ. 133, 225-239 (2013).

21. J. K. Choi et al., "Application of the geostationary ocean color imager (GOCI) to mapping the temporal dynamics of coastal water turbidity," Remote Sens. Environ. 146, 24-35 (2014).

22. R. P. Stumpf, G. Gelfenbaum, and J. R. Pennock, "Wind and tidal forcing of a buoyant plume, Mobile Bay, Alabama," Cont. Shelf Res. 13, 1281-1301 (1993).

23. D. K. Clark et al., "MOBY, a radiometric buoy for performance monitoring and vicarious calibration of satellite ocean color sensors: measurement and data analysis protocols," in Ocean Optics Protocols for Satellite Ocean Color Sensor Validation, J. L. Mueller, G. S. Fragion, and V. R. Mc Clain, Eds., NASA T/M 2003-211621/Rev4-Vol. V1, pp. 3-34, Goddard Space Flight Space Center, Greenbelt, Maryland (2003).

24. S. Ahmed et al., "Evaluation of VIIRS ocean color data using measurements from the AERONET-OC sites," Proc. SPIE 8724, 87240L (2013).

25. R. Arnone et al., "Monitoring bio-optical processes using NPP-VIIRS and MODIS-Aqua ocean color products," Proc. SPIE 8724, 87240Q (2013).

26. R. Arnone et al., "Sensitivity of calibration gains to ocean color processing in coastal and open waters using ensembles members for NPP-VIIRS," Proc. SPIE 9111, 911105 (2014). 
27. S. D. Ladner et al., "Inter-satellite comparison and evaluation of Navy SNPP-VIIRS and MODIS-aqua ocean color properties," Proc. SPIE 9111, 911107 (2014).

28. B. N. Holben et al., "AERONET-A federated instrument network and data archive for aerosol characterization," Remote Sens. Environ. 66(1), 1-16 (1998).

29. G. Zibordi et al., "AERONET-OC: a network for the validation of ocean color primary products," J. Atmos. Oceanic Technol. 26(8), 1634-1651 (2009).

30. Z. Lee et al., "Removal of surface-reflected light for the measurement of remote-sensing reflectance from an above-surface platform," Opt. Express 18(25), 26313-26324 (2010).

31. Z. P. Lee et al., "An inherent-optical-property-centered approach to correct the angular effects in water-leaving radiance," Appl. Opt. 50(19), 3155-3167 (2011).

32. G. Zibordi et al., "AERONET-OC: an overview," Can. J. Remote Sens. 36(5), 488-497 (2010).

33. P. J. Werdell et al., "Generalized ocean color inversion model for retrieving marine inherent optical properties," Appl. Opt. 52, 2019-2037 (2013).

34. J. Bowers et al., "Regional vicarious gain adjustment for coastal VIIRS products," Proc. SPIE 9111, 911114 (2014).

35. H. R. Gordon and M. Wang, "Retrieval of water-leaving radiance and aerosol optical thickness over the oceans with Sea-WiFS: a preliminary algorithm," Appl. Opt. 33, 443-52 (1994).

36. R. P. Stumpf et al., "A partially coupled ocean-atmosphere model for retrieval of water-leaving radiance from SeaWiFS in coastal waters," NASA Tech. Memo, S. B. Hooker and E. R. Firestone, Ed., pp. 51-59, NASA Goddard Space Flight Center, Greenbelt, Maryland (2003).

37. R. A. Arnone et al., "Coastal optical properties using SeaWiFS," in Ocean Optics XIV, SPIE, Kona, Hawaii (1998).

38. P. J. Werdell et al., "Regional and seasonal variability of chlorophyll-a in Chesapeake Bay as observed by SeaWiFS and MODIS-aqua," Remote Sens. Environ. 113(6), 1319-1330 (2009).

39. Z. P. Lee et al., "Robust approach to directly measuring water-leaving radiance in the field," Appl. Opt. 52, 1693-1701 (2013).

40. M. Ondrusek et al., "Report for: dedicated JPSS VIIRS ocean color calibration/ validation cruise," NOAA Technical Report NESDIS 146, Center for Satellite Applications and Research, Washington D.C. (2015).

41. J. E. O'Reilly et al., "Ocean color chlorophyll algorithms for SeaWiFS," J. Geophys. Res. 103(C11), 24937-24953 (1998).

42. Z. P. Lee, K. L. Carder, and R. Arnone, "Deriving inherent optical properties from water color: a multi-band quasi-analytical algorithm for optically deep waters," Appl. Opt. 41, 5755-5772 (2002).

43. H. R. Gordon and D. K. Clark, "Remote sensing optical properties of a stratified ocean: an improved interpretation," Appl. Opt. 19, 3428 (1980).

44. J. L. Mueller, C. C. Trees, and R. A. Arnone, "Evaluation of coastal zone color scanner diffuse attenuation coefficient algorithms for applications to coastal waters," Proc. SPIE 1302, 72-78 (1990).

45. R. W. Austin and P. J. Petzold, "The determination of the diffuse attenuation coefficient of seawater using the coastal zone color scanner," in Oceanography from Space, J. F. R. Gower, Ed., pp. 239-256, Plenum Publishing Corporation, New York (1980).

46. P. W. Werdell and S. W. Baily, "An improved in-situ bio-optical data set for ocean color algorithm development and satellite data product validation," Remote Sens. Environ. 98, 122-140 (2005).

47. R. Arnone et al., "Surface biomass across the Coastal Mississippi shelf," Proc. SPIE 9827, 98270Z (2016).

48. H. Yang, R. Arnone, and J. Jolliff, "Estimating advective near-surface currents from ocean color satellite images," Remote Sens. Environ. 158, 1-14 (2015).

49. M. Kamachi, "Advective surface velocities derived from sequential images for rotational flow field: limitations and applications of maximum-cross-correlation method with rotational registration," J. Geophys. Res. 94(C12), 18227-18233 (1989).

50. S. W. Bailey and P. J. Werdell, "A multi-sensor approach for the on-orbit validation of ocean color satellite data products," Remote Sens. Environ. 102, 12-23 (2006). 
51. X. Lou and C. Hu, "Diurnal changes of a harmful algal bloom in the East China Sea: observations from GOCI," Remote Sens. Environ. 140, 562-572 (2014).

52. J.-K. Choi et al., "Application of the geostationary ocean color imager (GOCI) to mapping of temporal dynamics of coastal water turbidity," Remote Sens. Environ. 146, 24-35 (2014).

Robert Arnone is a researcher professor at the University of Southern Mississippi with 42 years of experience in ocean satellite calibration, ocean optics, and integration which physical models. He heads USM Ocean Weather Laboratory and is a cochair of SPIE Ocean Sensing and Monitoring, with degrees in geophysics, geology (Georgia Tech, Kent State), and former ocean sciences branch head at Naval Research Laboratory.

Ryan Vandermuelen is a research scientist in the Ocean Ecology Laboratory at NASA Goddard Space Flight Center. His work has focused on the calibration/validation of space-borne sensors, real-time production, and distribution of satellite data products for adaptive sampling, advanced algorithm development and implementation, in situ validation of optical properties, radiometric protocol development, and quantitative coupling of physical circulation models to bio-optical processes.

Inia Soto received her BS degree in biology and education from the University of Puerto Rico, Mayaguez. She received her MS and $\mathrm{PhD}$ degrees in biological oceanography at the University of South Florida. Currently, she is a postdoctoral researcher in the division of marine science, the University of Southern Mississippi. Her research interests include ocean color satellite remote sensing of coastal ecosystems with emphasis in phytoplankton blooms and river dominated ecosystems.

Sherwin Ladner is an oceanographer in the oceanography division at the Naval Research Laboratory with 23 years of experience in satellite image, glider/in situ data processing and analysis, satellite calibration, processing and algorithm validation, ocean optics, 3-D optical modeling/forecasting and Navy fleet transitions. He received his BS degree in mathematics from the University of Southern Mississippi. He has experience with several satellite processing packages, in situ radiometric and optical sensors, models and satellite sensors.

Michael Ondrusek is an oceanographer for the NOAA Center for Satellite Applications and Research (STAR). He served as the division ocean color science team lead and the ocean color product oversight panel cochair from 2006 to 2011, the Marine Optical Buoy PI from 2007 to 2010, and the JPSS VIIRS Cal/Val annual cruise chief scientist. His research interest includes ocean color calibration and validation, satellite ocean color product algorithm development, and coastal ecology.

Haoping Yang received his $\mathrm{PhD}$ in aerospace engineering and mechanics in 2008 and his MS degree in fluid mechanics in 2004 from the University of Minnesota. He worked as an ocean modeler at NOAA/AOML from 2008 to 2012. He was a postdoctoral research associate in 2013 and an assistant research scientist in 2014 at the University of Southern Mississippi. Currently, he is a senior mechanics $R \& D$ engineer at Banzan International Group Corporation. 